\title{
Des-Bordes urbanos: un concepto en construcción
}

\section{Urban unboundings: a concept under construction}

\author{
José María López Medina*
}

Fecha de recepción: 30-04-2014 - Fecha de aceptación: 18-05-2015

Hábitat y Sociedad (ISSN 2173-125X), n. ${ }^{\circ}$ 8, noviembre de 2015, pp. 15-41.

\section{Summary}

The expression urban unboundings is working as a driving force for a collective reflection about urban peripheries in Latin America and Spain: a reflection which intends to generate useful knowledge that can be applied in terms of diagnosis and intervention.

The notion of limit, inherent to town planning and revitalized today from an ecological point of view, as well as the concept of border, which takes us back to binomials of high theoretical relevance, such as inclusion-exclusion and centre-periphery, engage with the metaphor urban unboundings to shine a light on new perspectives of analysis.

To consider the peripheral city in terms of unboundings leads us to wonder not just what unbounds and how, but also for what reason and for whom. In this regard, it introduces a political vision that enables urban phenomena to be interpreted in terms of the articulation of actors and balances of power, inherent in the mechanisms of control and planning. This in turn allows us to interpret the phenomenon as desirable or non-desirable depending on social equality and environmental sustainability.

From this type of speculative analysis, in line with the logic of each local context, are derived reflections and tools that can be useful for the policy, project and management of urban peripheries.

\section{Key words}

Urban unboundings, Emergency, Periphery, Research, Sustainability, Habitat

\section{Resumen}

La expresión desbordes urbanos está funcionando como motor de una reflexión colectiva sobre las periferias urbanas iberoamericanas que pretende generar conocimiento útil y aplicable en términos de diagnóstico e intervención.

La noción de límite, consustancial a la disciplina urbanística y hoy revitalizada en claves ecológicas, así como el concepto de frontera, que remite a binomios de gran relevancia teórica como inclusiónexclusión o centro-periferia, entran en diálogo con la metáfora desbordes urbanos para alumbrar nuevas perspectivas de análisis.

La lectura de la ciudad periférica en claves de desborde invita a preguntarse no solo qué se desborda y cómo, sino para qué y para quién. En este sentido introduce una visión política que permite interpretar los fenómenos urbanos en términos de articulación de actores y equilibrios de poder, subyacentes a los mecanismos de control y planificación. Y esto nos permitirá interpretar al fenómeno como deseable o no deseable en términos de igualdad social y viabilidad ecológica.

De este tipo de análisis teórico, situado en la lógica de cada contexto local, se derivan reflexiones e instrumentos útiles para la política, proyecto y gestión de las periferias urbanas.

\section{Pallabras clave}

Desbordes urbanos, Emergencia, Periferia, Investigación, Sostenibilidad, Hábitat

\footnotetext{
* Investigador del grupo ADICI (HUM810). Datos de contacto: c/ Elvira, 68, 3. ${ }^{\circ}$, 18010, Granada. E-mail: josemalo.es@ gmail.com.
} 


\section{Introducción: la red iberoamericana (des)Bordes urbanos}

Este texto se enmarca en el trabajo de la red "(des)Bordes urbanos. Política, gestión y proyecto en la ciudad de la periferia” (en adelante, dBU), encuadrada en el programa CYTED, ${ }^{1}$ cuya convocatoria de 2011 puso el foco en el diagnóstico e intervención sobre las periferias urbanas (figura 1) en claves de sostenibilidad. Conforman la red varios grupos de perfil profesional y académico procedentes de distintas regiones de Iberoamérica, y nace con el propósito de compartir y generar conocimiento útil sobre el objeto de estudio: conceptos, instrumentos de análisis, aportes metodológicos y directrices de intervención.
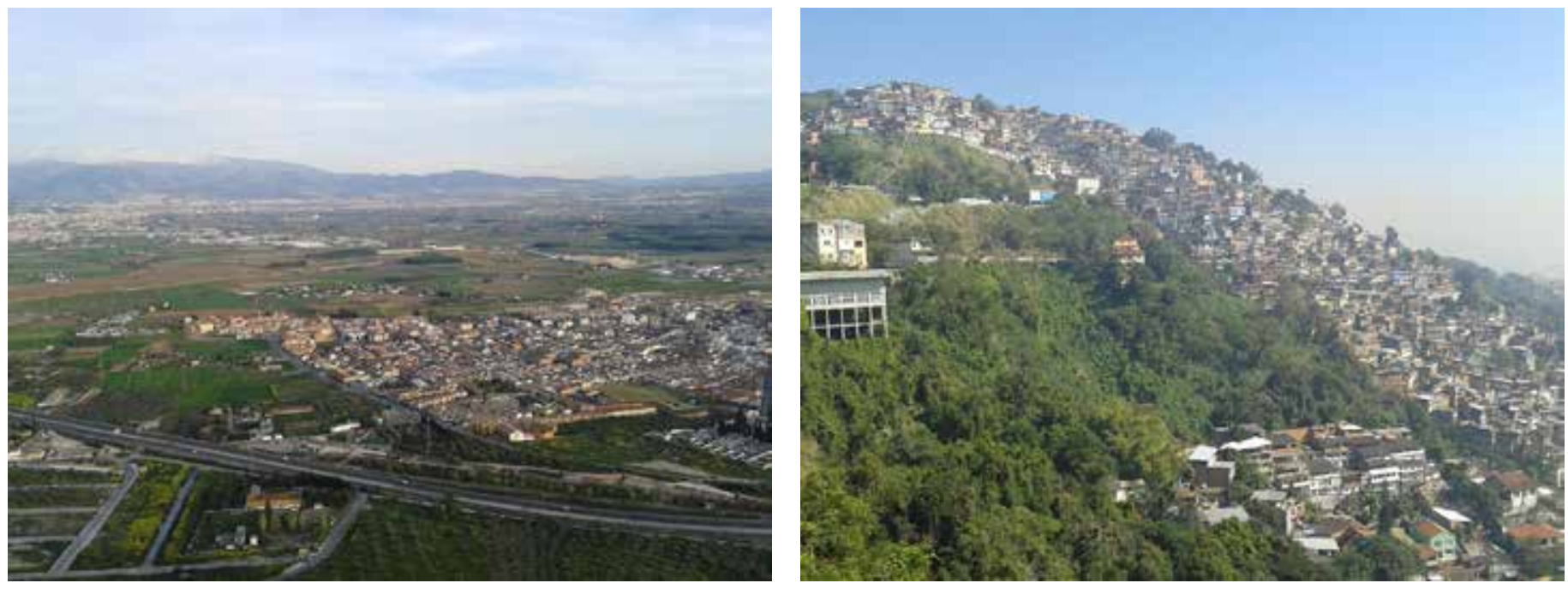

Figura 1. Distintas situaciones de periferia urbana. Área metropolitana de Granada, España (izquierda) y Río de Janeiro, Brasil (derecha). Fuente: Elaboración propia.

1 Programa Iberoamericano de Ciencia y Tecnología para el Desarrollo (http:/ / www.cyted.org/).

2 Gestión sostenible de: 1/ bases de datos sobre biodiversidad, 2/ las actividades mineras, 3/ los espacios urbanos periféricos, y 4/ las áreas de bosque para la captación de carbono

3 La iniciativa fue del equipo uruguayo, coordinado por el arquitecto Salvador Schelotto, de la Facultad de Arquitectura de la Universidad de la República (UdelaR).
La convocatoria de CYTED sitúa la temática de los "espacios periféricos iberoamericanos" en un bloque cuyo enunciado enfatiza la dimensión ambiental de la sostenibilidad y su gestión en los ámbitos urbanos de borde. Nuestra línea de investigación se inscribe dentro del área temática "Desarrollo Sostenible, Cambio Global y Ecosistemas", que persigue resultados orientados a "minimizar el impacto sobre el medioambiente y la biodiversidad durante los procesos de producción y consumo de bienes y servicios" (CYTED, 2011, p. 11), en una perspectiva que parece cercana a los enfoques conciliadores del desarrollo sostenible (Ojeda, 1999). En ese marco se establecen cuatro líneas de investigación, ${ }^{2}$ una de ellas orientada a la gestión sostenible de los espacios urbanos periféricos, que se marca como objetivo general:

El desarrollo de políticas y modelos de gestión integral para el desarrollo sostenible de espacios urbanos periféricos iberoamericanos con la participación conjunta de autoridades nacionales y locales, académicos, centros de investigación, ONG y poblaciones locales (CYTED, 2011, p. 11).

En síntesis, la convocatoria enfatiza el papel de los espacios periféricos en la lucha por la sostenibilidad urbana y explicita la necesidad de apoyar las políticas en criterios de interdisciplina, participación e integralidad.

La primera instancia de reflexión colectiva de la red dBU fue la formulación del proyecto, ${ }^{3}$ que sentó un plano de abordaje inicial para compartir avances en torno a "La gestión sostenible del hábitat en te- 
rritorios de borde" (Schelotto et al., 2011). La política, gestión y proyecto de la ciudad se abordan desde una visión compleja del hábitat periférico, que integra sus dimensiones físico-espacial-ambiental (urbs), socio-económico-cultural (civitas) y sociopolítica (polis) y sus interrelaciones (Capel, 2003; De Manuel, 2010).

Desde ese punto de partida se formula una propuesta que centra su perspectiva epistemológica en la mejora del hábitat de los sectores sociales más desfavorecidos; y en el plano teórico, enfatiza la condición compleja del hábitat y su gestión sostenible, entendiendo que es preciso:

1. Reconocer los vínculos entre los distintos planos de intervención, política, gestión y proyecto, y las potencialidades de su mutua interacción, esto es: cómo una determinada orientación de las políticas induce unas u otras formas de enfocar la gestión, o un buen proyecto puede sugerir modificaciones en las políticas o abrir nuevas posibilidades de gestión;

2. Reubicar el concepto de sostenibilidad considerando no solo su versión local sino también la global (Naredo, 2003), esto es: plantearnos el problema de la insostenibilidad del modelo civilizatorio hegemónico, situar ahí el papel de los asentamientos humanos y, en ese contexto, el de los ámbitos de periferia;

3. Partir de una noción amplia de periferia, capaz no solo de trascender la dimensión espacial e incluir la social, económica, política, cultural (y sus interacciones), sino también de enfrentar la condición compleja y cambiante de las realidades urbanas en términos de oportunidad para las estrategias de intervención.

Sin perder de vista este plano general, este texto se centra en la tercera de estas consideraciones. Como veremos, no será la noción de periferia el principal disparador del debate conceptual que ha servido para urdir la red, sino el concepto de desborde urbano, en continuo proceso de construcción y deconstrucción. El término nace de la intención de problematizar la idea de bordes urbanos mediante la anteposición del prefijo "(des)" ${ }^{4}$ Y pronto se habría de convertir en una imagen motora del debate del grupo que propició una relectura de las situaciones de hábitat periférico de cada una de las regiones participantes.

Este artículo pretende dar cuenta de esa discusión y presentar el concepto de (des)bordes urbanos tal como se ha venido construyendo y utilizando, tomando como punto de partida la reflexión colectiva del grupo. En parte quiere ser un estado de la discusión, a partir de los resultados recogidos en publicaciones y actas de encuentros y asambleas, de forma que muchos de los aspectos desarrollados a continuación ya fueron apuntados desde los primeros debates, ${ }^{5}$ si bien aquí se articulan y se amplían en un texto unitario. ${ }^{6}$

\section{Los espacios urbanos periféricos como punto de partida}

El concepto de periferia cuenta con amplios desarrollos pluridisciplinares que no corresponde abordar aquí. Pero nos interesa recordar que, en su trasfondo económico, remite a las teorías centro-periferia que elaboró la escuela estructuralista de la CEPAL (Cavalcanti, 2005) en respuesta a la visión que presentaba el subdesarrollo como un estadio previo del desarrollo (Rist, 2002): los centros mundiales de la economía indus-
4 Más tarde supimos que la expresión DEsBORDES URBANOS había sido acuñado años atrás por el arquitecto Daniel Zarza (2001), como llamada para una sugerente reflexión al respecto del proyecto de los bordes de la ciudad.

5 En todo caso, remito a los textos originales a los que se hace referencia, particularmente a los monográficos editados por la revista Vivienda Popular, "(des)Bordes Urbanos 01 y 02 ”, que constituyen un esfuerzo colectivo de agrupación de las reflexiones de la red.

6 Conviene asimismo señalar que esta reflexión, aun con sus vínculos y referencias a Latinoamérica, se elabora fundamentalmente desde y a partir de la realidad andaluza y española. 
Figura 2. Deterioro y estigma de los viejos conjuntos habitacionales del siglo XX. Izquierda: Ciudad Evita (La Matanza, Buenos Aires). Fuente: P. Bagnera. Derecha: Barriada Martínez Montañés (Polígono Sur, Sevilla). Fuente: E. de Manuel.

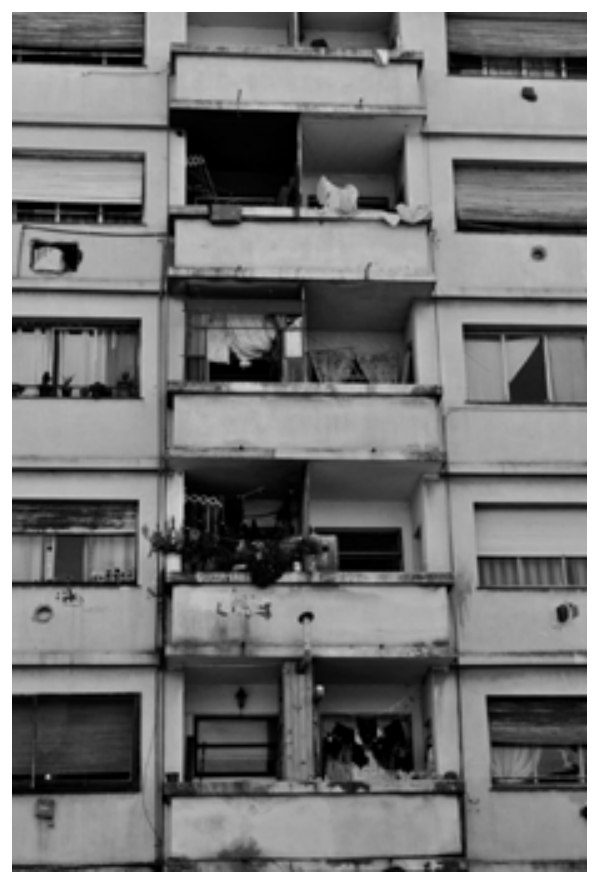

7 Caracterización que bien podría incluir también el calificativo de urbano, por oposición a la condición periférica del mundo rural.

8 Es por tanto una idea formulada desde el centro. Gabriel Feltran (2013) explicaba que durante mucho tiempo "Periferia es un concepto no asumido por la población que vive allî”.

9 Lo que Félix Arias denominó “La 'permanencia' histórica de los barrios desfavorecidos" (http://habitat.aq.upm. es/bv/gbd15.html) trializada y de servicios se explican por oposición a periferias con una economía de base extractiva. Estas periferias quedaron sujetas a relaciones de dependencia y dominación que hoy se prolongan a través de múltiples formas de "colonialidad global" (Grosfoguel, 2006) por parte de un capitalismo que Grosfoguel detalla como "sistema-mundo Europeo/Euro-norteamericano moderno/colonial capitalista/patriarcal" 7 (ob. cit.). La hegemonía global de esta cosmovisión, aun en sus voces críticas, atribuye una condición periférica, subalterna y silenciada al resto de las culturas del planeta (Spivak, 1988). Estimo oportuno situar en este marco la reflexión sobre los espacios urbanos periféricos, entendidos como expresiones locales de dinámicas de alcance global.

La primera noción de periferia urbana aparece para aludir a los ámbitos semiurbanizados que a partir de la revolución industrial surgen entre la ciudad tradicional y el medio rural. ${ }^{8}$ Es un concepto inherente al urbanismo como área de conocimiento y acción política, surgido en las últimas décadas del siglo XIX en respuesta a los conflictos y desafíos de la ciudad industrial (Hall, 1996). Es entonces cuando comienza a configurarse la idea de las periferias urbanas como áreas carentes, desordenadas y marginales. Esta noción de periferia se caracteriza a partir de las variables de distancia, dependencia y deficiencia en relación a un centro urbano (Arteaga, 2005, p. 101), una noción que aún conserva vigencia en el lenguaje técnico y el coloquial, debido a la posterior cronificación de muchos de estos sectores como ámbitos urbanos deficitarios. ${ }^{9}$

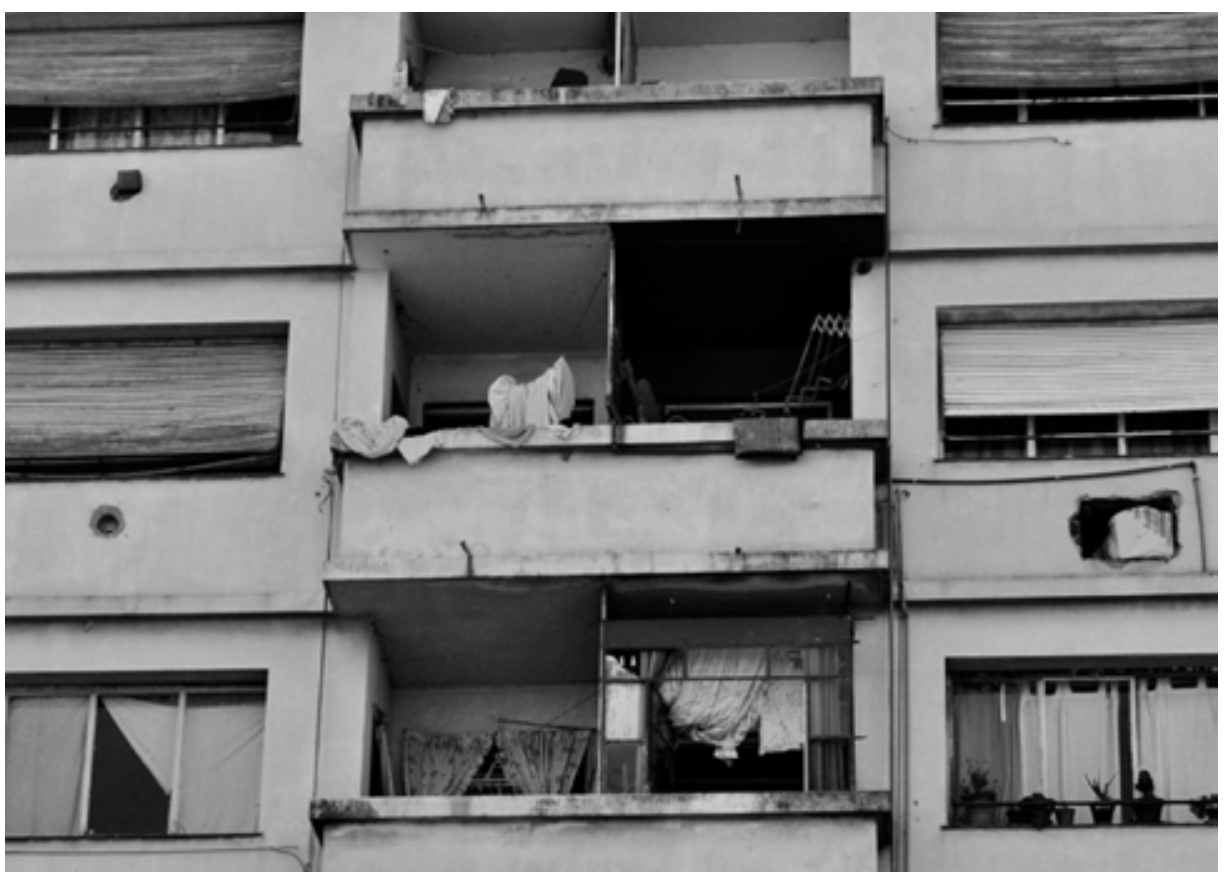

A partir de mediados del siglo XX, las operaciones de crecimiento urbano a base de conjuntos de vivienda social, primero de promoción pública y más tarde privada, dibujaron un paisaje de polígonos residenciales que en algunos casos, con el tiempo y las luchas vecinales, lograron integrarse en los tejidos urbanos (Castrillo, 2010), pero en otros giraron hacia graves situaciones de exclusión urbana (figura 2) debido a una conjunción de circunstancias que incluye enfoques políticos errados (Torres, 2013).

En el caso español, a partir de los años 90 los conjuntos habitacionales periféricos serán objeto de intervención estatal y de debate académico y profesional. La periferia será reivindicada desde su espe- 
cificidad como espacio de oportunidad y pieza activa en el proyecto contemporáneo de la metrópoli. Es entonces cuando aparecen, desde el ángulo proyectual, los aportes del entorno de Solá-Morales (1992) en los cursos y publicaciones sobre el proyecto de la periferia, y, desde la perspectiva de la gestión pública, las primeras generaciones de políticas de rehabilitación, precursoras de las posteriores figuras de regeneración urbana integrada. ${ }^{10}$

Desde los primeros debates de la red dBU se estableció la distinción entre una noción de periferia urbana definida en el sentido topológico o una periferia que se define por atributos (materiales, socioeconómicos o culturales) (Schelotto, 2013). En el contexto español, los ámbitos de borde hoy se corresponden con los espacios agrarios periurbanos y las áreas semiurbanizadas del borde metropolitano: lo que Fariña (2014) ha reconocido como el territorio correspondiente al "área de interfase entre la naturaleza protegida y la ciudad tradicional", una zona fragmentada en conjuntos monofuncionales de urbanización dispersa entre terrenos baldíos (figura 3), que se ha demostrado como un modelo altamente ineficiente y vulnerable a la crisis energética, lo que le augura un relevante papel como ámbito de acción política y actividad investigadora. ${ }^{11}$

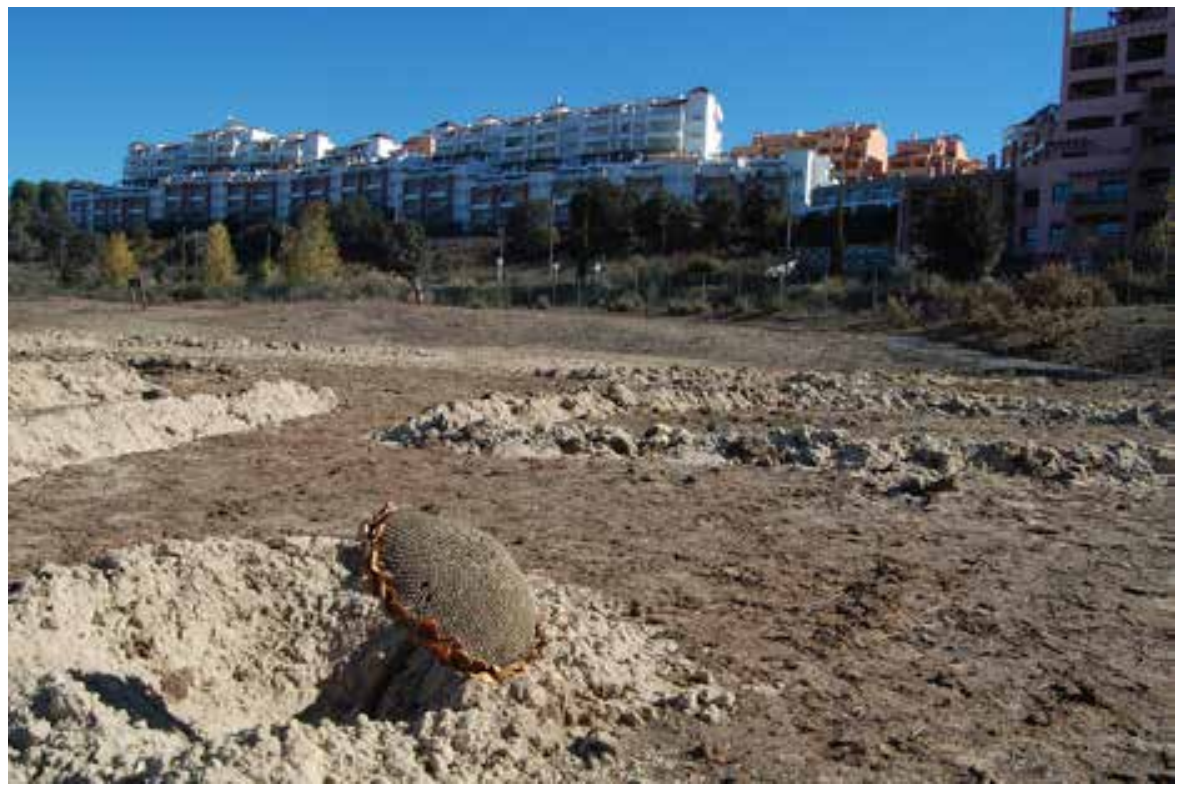

Pero, decíamos, también existe una noción de periferia urbana definida por atributos. Se refiere a aquellos territorios que, aun cuando puedan ocupar posiciones de centralidad urbana, presentan, más allá de sus fortalezas y potencialidades, algún grado de deficiencia o desequilibrio en términos de funcionalidad urbana o habitacional. Si nos ceñimos a la función residencial, estaríamos hablando de ámbitos que padecen situaciones de precariedad habitacional, urbana y/o ambiental desde algún punto de vista: tenencia insegura (de la tierra y/o de la vivienda), acceso a suministros precario o inseguro, patologías graves en la vivienda, espacio público deficiente, movilidad obligada, ausencia de dotaciones cercanas, etc. En definitiva, insuficiencia en el acceso a la satisfacción de las necesidades fundamentales relacionadas con el hábitat, lo que Julián Salas denomina carencias en habitabilidad básica (Gesto y Perea, 2012, pp. 13-14). La diversidad de posiciones que ocupan en la trama urbana estas situaciones de periferia sociohabitacional
Figura 3. Medina Elvira Golf Resort (Atarfe, Granada), ejemplo extremo de la urbanización especulativa de hace una década: una promoción fallida de cientos de viviendas, sin ciudad y sin habitantes, levantada entre intersticios metropolitanos. Fuente: Koldo Larrea.

10 Políticas hoy en proceso de evaluación con perspectiva de conjunto a través de varias líneas de investigación, como la coordinada por A. Hernández Aja desde el Departamento de Urbanística y Ordenación del Territorio (Universidad Politécnica de Madrid) (http://www2. aq.upm.es/Departamentos/Urbanismo/ blogs/re-hab/proyectos-investigacion). 11 Un área de investigación que ya arroja resultados de interés, como Muxí (2013) o MED European Program (2013). 


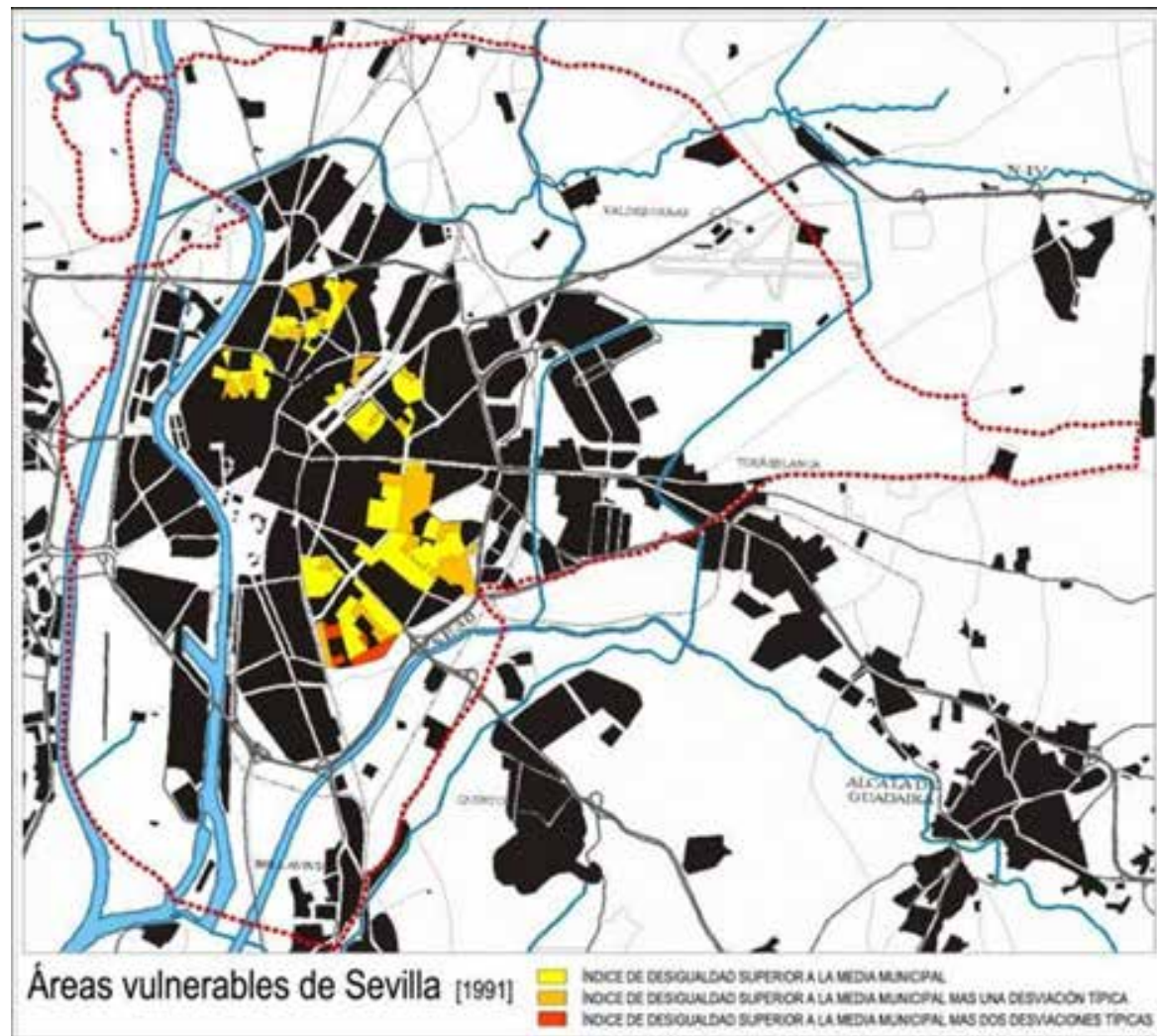

Figura 4. Mapa de las áreas vulnerables de Sevilla (según censo de 1991). Fuente: Elaboración propia. es muy amplia. José Torres da cuenta de ello en el caso de Sevilla (figura 4) cuando identifica cinco tipologías distintas de áreas vulnerables: la ciudad histórica, los barrios de autoconstrucción, asentamientos mixtos en el extrarradio, las barriadas de promoción pública y los polígonos de vivienda social (Torres, 2013, p. 159 y sucesivas).

Partimos, por tanto, de una noción amplia de espacio urbano periférico, que comprende, en síntesis, desde las situaciones de borde metropolitano, territorios suburbanizados y en transición o conflicto con el espacio agrario o natural, hasta todo el espectro de problemáticas de periferia social vinculadas al hábitat. Una noción que, además, aquí se ha descrito sobre todo a partir de la realidad andaluza, pero que presenta sus lecturas y singularidades en cada región iberoamericana.

\section{Elaborando el concepto de desbordes urbanos}

Relacionar, relacionar siempre, era un método más rico, incluso a nivel teórico, que las teorías blindadas, guarnecidas epistemológica y lógicamente, metodológicamente aptas para afrontar lo que fuere salvo, evidentemente, la complejidad de lo real.

Edgar Morin (1990, p. 59)

En el primer encuentro de los grupos españoles de la red dBU, celebrado en Sevilla en 2012, el geógrafo Juan Ojeda explicaba que cuando aún no se tiene claro un concepto van apareciendo metáforas, un mecanismo que opera como una táctica previa de aproximación y tanteo (Ojeda, 2009). "Tendamos a ser hermeneutas", proponía, invitando a adoptar una actitud interpretativa que nos permitiera identificar los que podamos considerar como fenómenos nucleares de la ciudad contemporánea que requieren abordajes específicos. En esa tarea, la expresión "desbordes urbanos" se ha revelado como una metáfora útil, una imagen motora que nos ha resultado una fecunda herramienta interpretativa. De ahí que la consideremos un concepto-en-construcción. Este texto, por tanto, necesariamente más cercano a un ensayo que a una investigación científica, no pretende, como afirma Morin, blindar una teoría sobre la idea de desbordes urbanos, sino mostrar su potencialidad, reseñar los debates que ha generado y ofrecerla como concepto instrumental de cara a enfocar el reto de la gestión urbana sostenible.

Siendo ambos conceptos de carácter topológico, frente a la noción estática de periferia, el de desborde trae implícita una serie de varia- 
bles que lo revelan como un concepto más dinámico y complejo, ya que introduce el factor tiempo, así como las ideas de crecimiento y de control. Hablar de desborde implica hablar de procesos y de relaciones de poder. No es un concepto de posición sino de cambio; quizá ahí resida su potencial para dinamizar una reflexión orientada en último término a la transformación del hábitat.

\subsection{Antecedentes}

Comenzaré enumerando un breve repaso sobre algunas aportaciones en la utilización y conceptualización del término desborde desde la perspectiva que nos interesa.

La primera de ellas es la noción de desbordes populares. El término desborde aplicado a las ciencias sociales trajo un concepto de la geografía - las inundaciones provocadas por la crecida de un curso o una balsa de agua - para ilustrar un fenómeno espontáneo e imprevisto protagonizado por un sector amplio de la sociedad. En este área de conocimiento su uso más extendido es la expresión desborde popular, que encuentra su origen en el texto del antropólogo peruano José Matos Mar "Desborde popular y crisis del Estado" (1984). El autor acuña la expresión para interpretar la transformación que experimenta la ciudad de Lima desde los años 40-50 del siglo XX con la inmigración y urbanización (física y cultural) de las clases populares campesinas a través del despliegue de sus estrategias de supervivencia. Este desborde popular, que implica producción del espacio, tiene un fuerte arraigo en procesos netamente urbanos que contienen tanto una dimensión social como territorial. En este sentido, buena parte de las acepciones que hoy inspira la expresión desborde urbano ya estaban implícitas en el sentido que le dio Matos Mar hace tres décadas.

Posteriormente, ha tendido a prevalecer la dimensión sociopolítica en el empleo del término, que ha sido utilizado en alusión a la emergencia de iniciativas contestatarias por parte de sectores oprimidos de la sociedad, como los llamados desbordes obreros o los feministas. Esta vertiente de investigación, que estudia, confronta y propone distintas perspectivas sobre el cambio social y su relación con el poder, utiliza la idea de desborde — no necesariamente el término- para referirse a un movimiento de cambio sociopolítico no controlado desde un centro, sino de naturaleza emergente, y cuenta con su propia tradición investigadora y notables desarrollos en las últimas décadas. ${ }^{12}$

Por su vocación operativa y su contribución a la construcción conceptual que nos ocupa, destacaremos las aportaciones recientes de Tomás R. Villasante, que desde la experiencia colectiva del CIMAS viene teorizando el concepto de desbordes creativos desde el ángulo metodológico (2006a, 2006b, 2014) con la intención de aportar claves y herramientas que resulten útiles a los procesos de cambio y emancipación social. Villasante (2014) elabora una reflexión que resalta lo metodológico por encima de lo ideológico y orienta el debate hacia la praxis, centrándose en las formas de hacer colectivamente. Ofrece para ello claves metodológicas, como interpretar los bloqueos y contradicciones iniciales en claves de oportunidad, y aporta herramientas para convertir los falsos dilemas en polilemas creativos que propicien salidas zigzagueantes. El propio autor asimila su noción de desbordes a las $r e-$ versiones y las transducciones de Jesús Ibáñez (Villasante, 2006b), si bien reconoce igualmente vínculos o convergencias con otras construcciones teóricas, provenientes del pensamiento poscolonial o el feminista,
12 Entre otros, Wallerstein (1996), Zibechi (2006, 2010), Holloway (2005), Encina y Ávila (2014). 
como las emergencias de Sousa Santos, o las transposiciones de Rosi Braidotti. Todas ellas "tienen casi el mismo sentido, y en todo caso el enfoque superador y transformador es muy semejante" (Villasante, 2014, p. 96).

La red dBU vino a sumarse a esta construcción colectiva de la idea de desborde tratando de profundizar en la propuesta de interpretaciones para los fenómenos urbanos contemporáneos. No se tardó en señalar criterios de distinción, en función de cuál sea su vector dominante, entre desbordes predominantemente espaciales o físicos y predominantemente sociales (Matarán et al., 2013; Schelotto, 2013), una primera perspectiva que ya permite registrar las notables diferencias existentes entre las regiones europeas y latinoamericanas. A este respecto, Zibechi señaló las nuevas territorialidades de los movimientos del Sur como "el rasgo diferenciador más importante (respecto de los viejos movimientos y de los actuales movimientos del primer mundo) y lo que les está dando la posibilidad de revertir la derrota estratégica del movimiento obrero, infligida por el neoliberalismo" (2007, p. 46):

Estos territorios son los espacios en los que se construye colectivamente una nueva organización de la sociedad. Los territorios de los movimientos, que existieron primero en las áreas rurales (campesinos e indios) y desde hace unos años están naciendo también en algunas grandes ciudades (Buenos Aires, Caracas, El Alto...), son los espacios en los que los excluidos aseguran su diaria supervivencia.

No ha sido hasta el último lustro que también en regiones del norte empiezan a emerger con mayor potencia, visibilidad y articulación redes populares, como las vinculadas a la agroecología, que suponen un movimiento de re-territorialización (Magnaghi, 2011; Matarán, 2013).

Ciñendo la idea de desborde a la "salida de manera imprevista y explosiva de una cosa a su exterior, o el sobrepaso de los límites que la contienen" ${ }^{13}$ y tomando como referencia toda el área ibérica y americana, bajo la denominación de desbordes predominantemente espaciales cabe englobar situaciones bien diversas de expansión descontrolada de la urbanización: desde el resultado de la autoproducción popular de vivienda en las periferias urbanas latinoamericanas, hasta los excesos financiero-urbanizadores del capitalismo global, que en España provocaron la burbuja inmobiliaria y que Fernández Durán (2006) acertó a retratar como un tsunami urbanizador, en una versión extrema de la expresión desborde urbano.

Y más allá de la expansión territorial, también cabe identificar fenómenos similares en el interior de la ciudad —en las que de hecho se dan igualmente procesos de producción material y simbólica del espacio-, como el crecimiento exacerbado de alguna de las funciones urbanas. Valga como ilustración la aparición de áreas monofuncionales, ya sea mediante el predominio excesivo de usos residenciales, la terciarización de los centros urbanos, el incremento desmedido de los usos turísticos en zonas históricas, o, sin variación significativa de la proporción de usos, la gentrificación o sustitución de unos perfiles de población por otros.

Siguiendo con los aportes de la red dBU, en el encuentro de Curitiba en 2013 se profundizará en la idea de desbordes sociales, así como en el reconocimiento del conflicto y su visión política; en este sentido se sugiere la expresión derecho al desborde como traslación terminológica del derecho a la ciudad (Schelotto [comp.], 2013).

13 http://es.wikipedia.org/wiki/DesPor su parte, Arias formula una aproximación teórica que recono- 
ce el desborde urbano como expresión de una situación latente que contiene algún tipo de desequilibrio y propicia la aparición de prácticas emergentes (2013, p. 17). En este sentido cabe afirmar que el desborde se presenta como una expresión radical de necesidad mas oportuni$d a d$, una necesidad entendida como catalizadora de "recursos no convencionales" (Max-Neef et al., 1998, p. 109). En esa dirección, a partir de una lectura ubicada en el derecho a la ciudad, se consideran ciertos desbordes como una manifestación de situaciones de precariedad y exclusión de derechos (Bagnera, 2013; Recalde, 2013).

Algunas aportaciones han subrayado otro aspecto de interés, relativo a cómo corresponde a cada contexto identificar las situaciones de desborde que le son propias, así como reconocer las prioridades y construir estrategias de intervención apropiadas (Lorenzo, 2013; Sugranyes, 2013). En una reflexión vinculada a la realidad argentina, Bagnera se ha referido al desborde como oportunidad en tanto espacio potencial para la intervención y "fundamentalmente como espacio de articulación interactoral" (2013, p. 28). De este modo, introduce la pregunta acerca de quién o quiénes producen el hábitat y los modelos de gestión, una cuestión que también ha destacado Lorenzo (2013, p. 49) y que retomaremos más adelante.

En definitiva, como acotación preliminar consideramos desborde urbano cualquier fenómeno concerniente al hábitat en el que un aspecto de la realidad urbana supera su demarcación inicial de forma acelerada y no controlada por ningún actor o instancia de decisión en particular. Puede afectar a una o varias dimensiones de dicha realidad, ya sea la capacidad de carga de un soporte físico-territorial, ya sea las pautas de acción de un cuerpo social, ya sea el equilibrio de usos o la funcionalidad de un sector urbano. Sobre esta base plantearemos distintas perspectivas y escalas de aproximación, comenzando por esbozar una breve interpretación del concepto en la escala planetaria.

\subsection{Escenario global: el desborde como rasgo civilizatorio}

El desborde nos remite a un fenómeno propio del comportamiento de los fluidos, un recurso que ha inspirado influyentes metáforas para interpretar la condición contemporánea. ${ }^{14}$ Jeremy Till ha descrito cómo "los contornos tradicionales se han disuelto, permitiendo flujos sin precedentes de capital, trabajo, mercancías e información” (Till, 2014, p. 51), mientras que el espacio urbano y político que producen estas nuevas condiciones "no tiene nada de líquido" (ob. cit.) y se muestra cada vez más rígido en sus formas de represión, mercantilización y control (Monedero, 2013). Sólido y líquido son dos caras de la modernidad en relación dialógica (Morin, 1990), que ayudan a comprender cómo unos bordes urbanos se vuelven más rígidos e infranqueables mientras que otros se disuelven, se ignoran o se sobrepasan.

La transgresión de los límites se nos muestra hoy como un rasgo característico de la civilización occidental. Latouche (2014) se ha referido recientemente a la ilimitación moderna como una combinación de formas de desmesura que rebasa todo tipo de límites, en una reflexión que en buena parte cabe interpretar como un desborde multidimensional: el geográfico, que se refiere a la transgresión de límites territoriales y que en parte incluye a los desbordes urbanos; el político, con unos estados-nación cuya soberanía se ve rebasada por los nuevos poderes transnacionales; el desborde de la cultura occidental, vehiculado en un proceso de globalización que la impone al resto de culturas;
14 Como la Modernidad líquida de Bauman (1999) o las Espumas y Burbujas de Sloterdijk (2003 y 2005). 
15 Término propuesto en 2000 por el Nobel de Química Paul Crutzen para designar la actual como una nueva era geológica, que estaría marcada por la inédita capacidad humana de incidencia sobre la biosfera.

16 “(...) nos harían falta de tres a seis planetas para generalizar el modo de vida occidental" (Latouche, 2014, p.69). Dicho de otro modo, para generalizar el nivel de consumo de España "sobrarían más de las dos terceras partes de la humanidad" (Riechmann, en http:/ /www.eldiario.es/ultima-llamada/Decrecimiento-suficiencia-consumismo_6_382571757.html, acceso 29.04.15).

17 El Earth Over Shoot Day estima que, actualmente, en agosto la humanidad "agota el presupuesto" ecológico anual de la naturaleza: http://www.footprintnetwork.org/es/index.php/GFN/page/earth_overshoot_day/.

18 Wallerstein, Immanuel (1997). El futuro de la civilización capitalista, pp. 79-80.

Barcelona: Icaria. Cit. por Riechmann (2006, p. 68). Cursivas del autor.

19 La frontera de la exclusión en las sociedades de la periferia europea se abre paso entre capas cada vez mayores de las clases medias, que hoy se ven desposeídas de trabajo, capital y vivienda.

20 Un incremento mundial de la urbanización que tiene, no obstante, su contrapunto en algunas "ciudades menguantes", que requieren abordajes específicos. Al respecto se puede consultar: http://elblogdefarina.blogspot.com.es/2015/02/ ciudades-menguantes.html. el desborde de los límites ecológicos en la era del Antropoceno, ${ }^{15}$ con consecuencias como el cambio climático o la superación de la capacidad de regeneración de la biosfera, expresada en indicadores como la huella ecológica del planeta, ${ }^{16}$ ya advertida en los años setenta en el primer Informe Meadows, o el más reciente de overshoot, su equivalente temporal $;{ }^{17}$ la superación de los límites de la economía real, colonizada por la lógica financiera de la sobreacumulación de capital; la deliberada ignorancia de los límites cognitivos y la pretendida omnipotencia de la tecnociencia; y, finalmente, el trasfondo ético y la transgresión de los límites morales.

Los señalados por Latouche se interrelacionan entre sí e interactúan junto a otros fenómenos planetarios de extralimitación, como la creciente demanda mundial de materias primas no renovables, o la explosión demográfica que en este siglo alcanzará cotas inéditas.

Jorge Riechmann viene desarrollando una detallada reflexión sobre las consecuencias de vivir en un "mundo lleno" (2006, p. 44), una expresión tomada del economista ecológico Herman E. Daly, haciendo notar que el choque contra los límites ecológicos coincide en el tiempo con otra colisión: el choque contra los límites sociopolíticos, analizado por diversos autores en términos de "conflictos de acumulación y legitimación del capitalismo tardío" (ob. cit., p. 45).$^{18}$ En este sentido, Santos $(2010$, p. 26) se ha referido a la aparición, en las democracias políticas liberales, de un fascismo social que se expresa, por un lado, en un precontractualismo que "bloquea el acceso a la ciudadanía a grupos sociales que antes $[\ldots]$ tenían la razonable expectativa de acceder a ella" (ibíd.); y por otro, en un postcontractualismo, que excluye sin perspectiva de retorno a grupos que estaban incluidos en el contrato social. ${ }^{19}$ La exclusión del acceso a derechos y recursos básicos de una parte creciente de la población mundial, no ya en sus regiones periféricas sino también en amplias áreas del centro, viene ensanchando una brecha social que Leonardo Boff (2000) acertó a describir como una auténtica bifurcación de la humanidad.

De la misma manera, la reacción en forma de búsqueda de respuestas y alternativas a esta acumulación de contradicciones, tiende a emerger como un movimiento contrahegemónico que, sobre el sustrato de las propuestas y praxis alternativas generadas tanto en el Norte (movimiento de transición, decrecimiento, feminismos) como en el Sur (movimientos indígenas, pensamiento poscolonial), adopta a su vez rasgos de desborde popular en expresiones como el Foro Social Mundial, la primavera árabe, el 15M (figura 5) o el movimiento Occupy.

Una visión sobre todo este conjunto de situaciones interrelacionadas nos invita a interpretar la multicrisis de civilización a la que nos dirigimos (Morin, 2011) como un escenario de Desborde Global. Un escenario que, teniendo en cuenta factores como los crecientes índices mundiales de urbanización ${ }^{20}$ — también "estamos llegando a los límites en lo que a desruralización del mundo se refiere" (Riechmann, 2006, p. 44) - y la relevante aportación de las ciudades a la huella ecológica global, presenta sin duda una importante dimensión urbana (Fdez. Durán, 2010). Y no solo porque gran parte de las situaciones descritas tengan lugar en escenarios urbanos, sino también porque afectan directa o particularmente a las ciudades, o porque es precisamente la acumulación metropolitana y la dinámica urbanizadora una de sus causas o catalizadores principales: son las ciudades las protagonistas territoriales del entramado económico-financiero y cultural de nuestro sistema urbano-agro-industrial (ibíd.). Ya en la Cumbre de Río en 1992 se enunció el conocido lema "la 


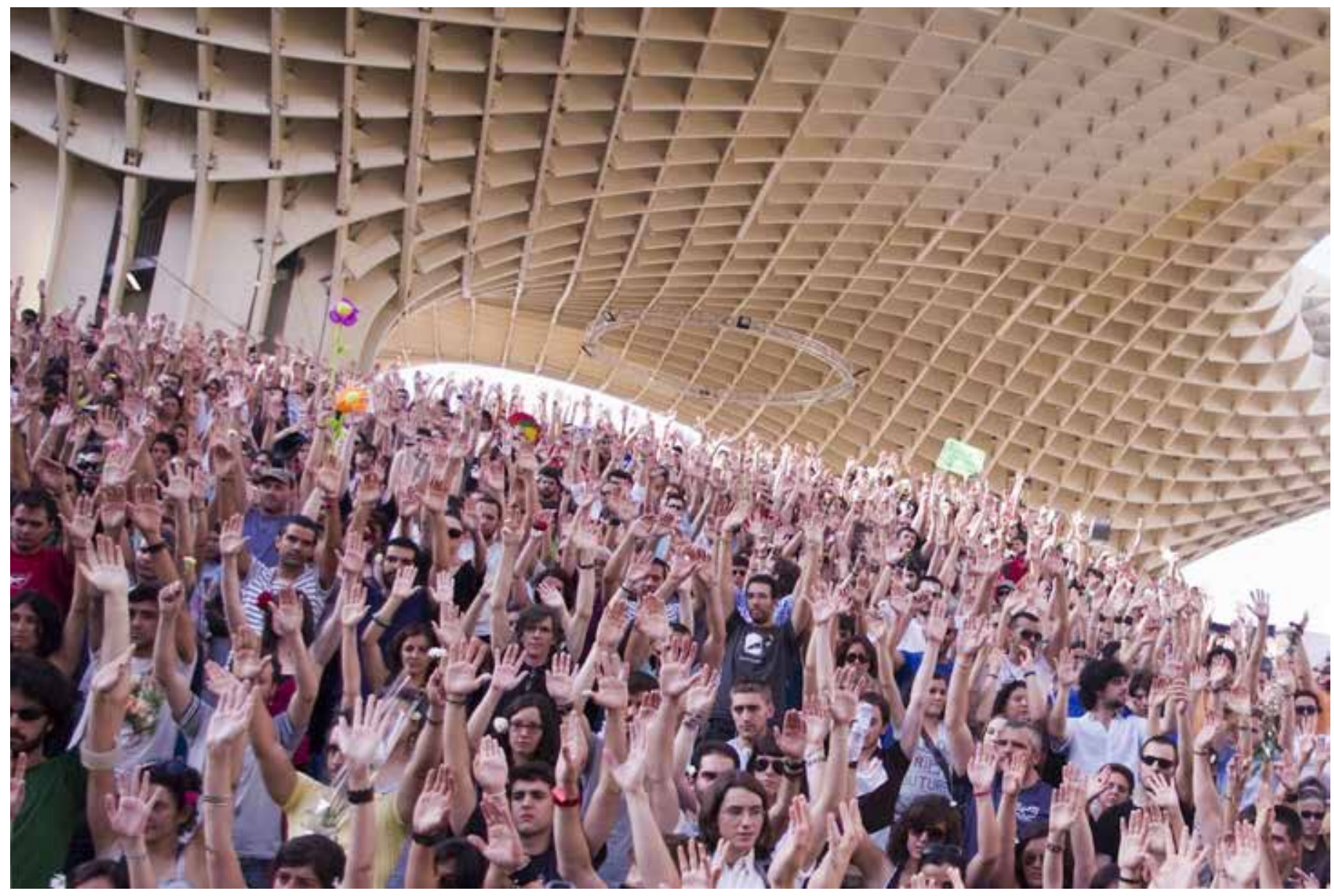

batalla de la sostenibilidad se ganará o se perderá en las ciudades”, y en el reciente $7 .^{\circ}$ Foro Urbano Mundial (WUF7) de 2014 se ha repetido "la mayoría de problemas de este mundo son urbanos" ${ }^{21}$ (incluido el de la pobreza a escala mundial, cada vez más urbana).

Siendo nuestro objeto de investigación la gestión urbana sostenible, la reflexión se centrará desde aquí en profundizar en algunas de estas cuestiones para desarrollar la idea de desborde urbano en la escala local y regional.

\subsection{Aproximaciones a la gestión sostenible de las periferias urbanas a partir de la idea de desborde}

Partiendo de una noción primaria de desborde urbano como crecimiento no controlado de un dominio sobre el contiguo, formularemos varias aproximaciones: 1) cuál es la naturaleza del fenómeno de desborde; 2) qué tipo de borde es el que se ve rebasado; 3) quién lo moviliza y a qué actores afecta; y 4) el desborde como cambio de paradigma.

Dedicaremos los siguientes apartados a cada una de ellas, y al final concluiremos, a modo de síntesis, una serie de criterios o pistas que pueden resultar útiles a hora de idear estrategias políticas, de gestión y de proyecto orientadas a la sostenibilidad de las periferias urbanas.

\subsubsection{Desde la complejidad y la emergencia: qué tipo de}

fenómeno es un desborde

El título de este apartado parafrasea a Jane Jacobs cuando se pregunta Qué tipo de problema es una ciudad en el último capítulo de su clá-
Figura 5. El movimiento 15M, paradigma de desborde social, en Sevilla ha logrado reapropiarse simbólicamente del espacio Metropol Parasol, un emblema local de la arquitectura globalizante. Fuente: http://logros. 15 m.cc/ (Licencia CC:BY-NC-SA 3.0).

21 http://elpais.com/elpais/2014/10/26/planeta_futuro/1414347828_753312.html. 
sico Muerte y vida de las grandes ciudades (2013, p. 467). La referencia no es casual, pues Jacobs y las teorías de la emergencia aportan la base de esta reflexión.

Los desbordes pertenecen al terreno de la acción, y en la medida en que son situaciones de cambio no controlado son fenómenos de naturaleza compleja. Morin explica que la teoría de la complejidad "no solamente pone el acento sobre la relación en detrimento de la sustancia, sino que también pone el acento sobre las emergencias, las interferencias, como fenómenos constitutivos del objeto" (1990, p. 76). En cualquiera de sus versiones, los desbordes se muestran como expresión de lo contingente e inesperado, de la incertidumbre como parte del objeto: "integrar lo aleatorio, tanto en su carácter de imprevisibilidad, como en su carácter de evento" (ob. cit., pp. 79-80). El binomio control-desborde tiene que ver con orden-desorden. Y la idea de desborde urbano señala una puerta de entrada de los saberes relacionados con lo urbano hacia el terreno de la complejidad.

Los desbordes son fenómenos emergentes, en el sentido en que lo ha planteado la ciencia y la teoría de la complejidad. Los sistemas emergentes son formas de funcionamiento grupal que no obedecen a ningún centro de control externo ni interno: son eventos en los que, de la interacción entre conductas individuales, resulta, o mejor, emerge un comportamiento colectivo (Johnson, 2003). En el sistema emergente hay un salto cualitativo a partir del crecimiento cuantitativo, en condiciones suficientes de densidad de interacciones entre individuos y conductas particulares. En un momento crítico se produce un salto de fase que constituye la emergencia.

Hablamos de emergencia en su doble acepción: imprevisto y generado de abajo arriba. Son fenómenos ascendentes y descentralizados, frente a los sistemas descendentes y centralizados. Resultan de interacciones espontáneas, mientras los segundos lo hacen de una planificación central. En este sentido se pueden inducir, pero no programar y controlar. Más que control, a lo sumo hablaríamos de gestión en la acción, de un manejo indirecto, asumiendo su dosis de azar. Reconocemos un ejemplo de este tipo de control inductivo en la rehabilitación del barrio San Martín de Porres (figura 6): cuando la Junta de Andalucía decide programar las intervenciones de rehabilitación de vivienda pública en función de que hayan sido solicitadas expresamente por la comunidad de vecinos en lugar de decidirlo desde una oficina central de planificación, se está operando mediante un criterio de control indirecto que introduce un estímulo a la autoorganización (Benítez, 2010).

Por último, en un sistema emergente puede haber factores de re-
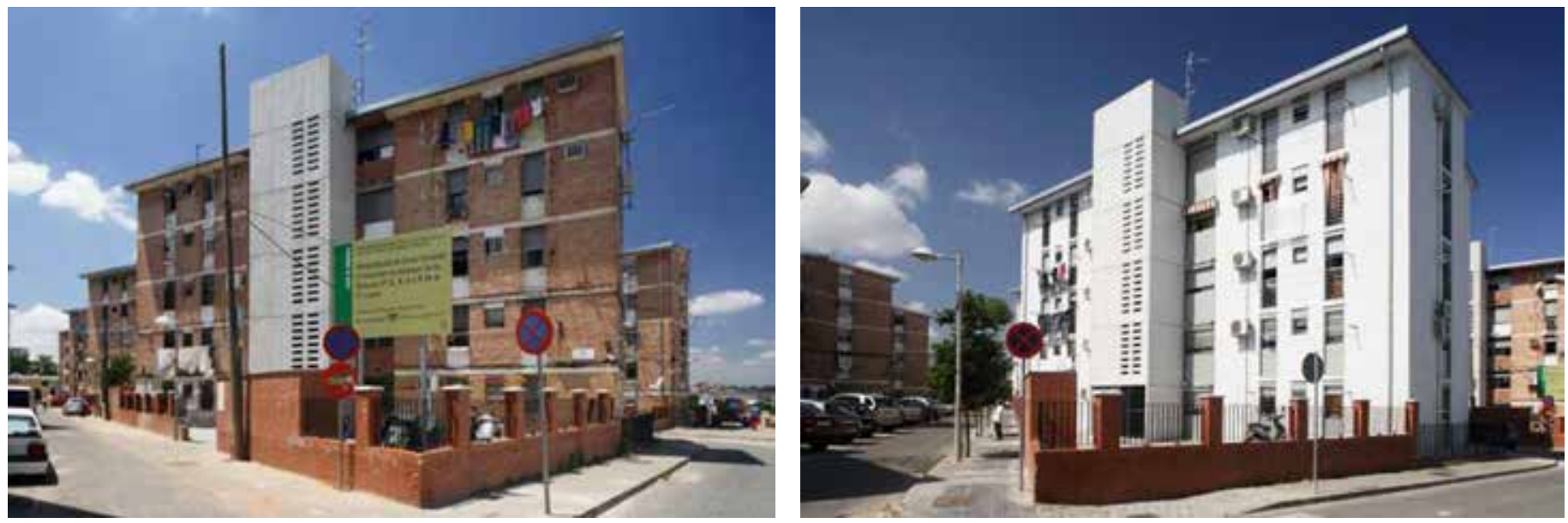
troalimentación positiva que continúan haciéndolo crecer indiscriminadamente, o puede haber una retroalimentación negativa, un feed-back que permite que el sistema aprenda y desarrolle una conducta adaptativa a la nueva situación, autogenerando una nueva estructura interna que responde al contexto, esto es, una conducta inteligente de escala superior. Hay entonces sistemas inteligentes que combinan crecimiento y autoorganización adaptativa, frente a sistemas con retroalimentación positiva, que generan pura acumulación sin estructura ni eco-adaptación (Johnson, 2003). Desde aquí parece explicarse la base de la insostenibilidad de un sistema como el capitalista, que propugna precisamente acumulación y desregulación.

Jacobs (2013) fue pionera en entender las ciudades como realidades complejas y emergentes. Desde esa lógica explicó el funcionamiento de los barrios y las metrópolis, la revitalización o deterioro de zonas urbanas, su tendencia a la diversidad o a la homogeneidad, o las claves de localización de áreas exitosas de comercio, abriendo una perspectiva de comprensión de la ciudad que hoy sigue vigente.

Pero la ciudad se construye a partir de la coexistencia de lógicas emergentes y lógicas centralizadas, un tema lúcidamente abordado por García-Bellido en su Coranomía (2007). El autor estudió la ciudad musulmana como un caso paradigmático de ciudad emergente, pues en la medina los mecanismos de control urbanístico no provienen de un plan director sino de unas reglas basadas en la doctrina coránica y la jurisprudencia sobre resolución de conflictos entre vecinos. En sus palabras, rige un paradigma urbanístico local aleatorio-incrementalista frente al paradigma holista-determinista, propio del urbanismo clásico y de algunos urbanismos modernos. Estamos frente a la expresión urbana de la tensión entre liberalismo y centralismo. Según García Bellido, la ciudad va incrementando su complejidad en la medida en que se va dotando de instancias superiores centrales de dirección-planificación, que se crean en los momentos en que se ve desbordado el umbral mínimo de tolerancia de esa sociedad (esa cultura en esa época) a los efectos resultantes de las lógicas emergentes. El propio urbanismo occidental como disciplina teórica y rama política nace como una respuesta centralizada a los problemas de salud pública de la emergente ciudad industrial (Hall, 1996).

Por último, también constituye un ejemplo de sistema emergente la lógica que subyace a los procesos de transformación social, ya sean los que conducen a un territorio o grupo social por una espiral de incremento de la degradación a base de retroalimentación positiva, como ocurrió en Polígono Sur (Torres, 2013), ya sean los que generan una espiral virtuosa de construcción colectiva como los procesos autogestionarios (Encina y Rosa, 2005), donde los dinamizadores aparecen como catalizadores de la interacción entre individuos y grupos sociales, alentando conjuntos más amplios de acción que tienden a combinar crecimiento y organización. Los momentos de devolución en las metodologías participativas cumplen el papel de la retroalimentación negativa.

En síntesis, lo que entendemos por desborde es un fenómeno de naturaleza emergente y de rápido crecimiento, que sigue una lógica ascendente y no centralizada, y se produce cuando, a partir de unas condiciones de contorno, una agregación suficientemente densa de conductas individuales supera un umbral crítico y tiene lugar una transición de fase. Se da entonces un cambio tanto cuantitativo como cualitativo respecto al sistema o estadio de equilibrio anterior, dando lugar 
a un sistema que puede ser adaptativo (inteligente) o bien meramente acumulativo.

\subsubsection{Desde los tipos de borde: límites y fronteras}

Desbordar implica superar un borde: centraremos ahora el foco de la reflexión en este punto. Resulta útil a este respecto recordar la distinción que Jose Luis Sampedro (1991) estableció entre la noción de limite y la noción de frontera, dos conceptos distintos que con frecuencia se tiende a confundir. Reduciendo la reflexión de Sampedro a una imagen, las fronteras son puertas y los límites son muros. Toda frontera (espacial, temporal, social, biológica, política, geográfica, etc.) es una convención que sirve para distinguir entre ámbitos diferentes de la realidad. La frontera admite la posibilidad de ser cruzada, permite la mixtura y el intercambio, y esto puede percibirse como una oportunidad o como una amenaza. La primera de estas dos sensibilidades presenta la condición fronteriza como una posición proclive a lo mestizo, a la innovación y la vanguardia. Esta idea se acerca al concepto de ecotono, proveniente de la ecología, que define las zonas de transición entre ecosistemas, donde estos registran su máxima interacción, y por tanto las de mayor riqueza e interés biológico (Odum, 1971; Holland et al. (Eds.), 1991). En esta dirección, Ojeda y Villa consideran que uno de los rasgos definitorios de la ciudad, como nodo territorial, es lo ecotónico o fronterizo, entendiéndola como "un lugar de encuentro y adaptaciones de ecosistemas, de personas libres, de ideas, de planes y de disidencias" (Ojeda y Villa, 2009).

Estos son atributos de la condición fronteriza, a la que opone Sampedro la condición del centro como tendente al conservadurismo, y propicia al dogmatismo y en última instancia a la inmovilidad. "Se configuran así dos estilos de vida: el fronterizo y el central" (Sampedro, 1991, p. 18). Ambos mantienen una relación dialógica, la que existe entre los polos conservación-transformación. La percepción de la frontera como amenaza, propia del estilo central, es más acusada cuanto más asimétricos son los territorios que separa. Las consecuencias más extremas de dicha percepción se traducen en su utilización como instrumento de segregación y control, propia de las ciudades y sociedades en la fase actual del capitalismo global (Montaner y Muxí, 2011). En su proceso de mercantilización, nuestros sistemas urbanos no contemplan límites al crecimiento pero multiplican sus fronteras internas imponiendo una lógica de la segregación. Son las fronteras calientes descritas por Claudio Caveri como rasgo civilizatorio (2002), que encuentra una de sus más trágicas expresiones en la violencia fronteriza de los flujos migratorios, que llevaba recientemente a Alba Rico (2014) a afirmar que " $[\ldots]$ las cifras dan cierta verosimilitud a la descripción del teólogo Hinkkelammert, quien habla de un 'genocidio estructural' en las fronteras".

Es la teoría poscolonial la que ha indagado el sentido y consecuencias de la noción radical de frontera instalada en la cultura occidental a través de la idea del "pensamiento abismal" (Santos, 2014). Occidente impone una cartografía legal y epistemológica mediante el trazado de una línea abismal que niega la existencia del otro lado, dejándolo más allá de la legalidad-ilegalidad y de la verdad-falsedad, generando una forma de exclusión radical sobre una parte de la humanidad para afirmarse a sí misma como sujeto universal (ob. cit, p. 18). La división 
entre zonas civilizadas y zonas salvajes es la lógica que explica las cercas entre las ciudades privadas fortificadas y los guetos urbanos.

Las fronteras son, entonces, zonas de separación que admiten ser cruzadas o desplazadas. No así los límites (Sampedro, 1991, p. 28):

Las fronteras tienen puertas, cuyo dios era Jano. Pueden ser superadas, asumidas, e incluso desplazadas, puesto que son producto de la conveniencia humana y se establecen para mejor interpretar lo real o para comodidad de la vida. En cambio los límites carecen de aberturas y no es lícito franquearlos: quien a ello se atreva corre un riesgo mortal para su cuerpo o para su espíritu, por haber violado lo sagrado [...].

De modo que el concepto de desborde cambia radicalmente de significado y de consecuencias según se refiera al rebasamiento de una frontera - en función del papel que esta cumpla—o a la superación de un límite.

Como vimos antes, sobrepasar límites es un rasgo característico de nuestras metrópolis y nuestra civilización. Vinculando ambos conceptos, Jorge Riechmann ${ }^{22}$ ha defendido "la conveniencia de un humanismo fronterizo, defensor a ultranza de la libertad humana y consciente de la finitud de nuestra vida situada en la frontera" (2004, p. 69), una consciencia de los límites entendida no como constreñimiento sino como oportunidad. Así lo recuerda una de las tesis de Toblach, ${ }^{23}$ citada por el propio Riechmann (2011, p. 97): "Solo dentro de límites se puede refundar la ciudad: el límite es un recurso". Recientemente ha venido a reforzar esta idea el ideólogo del decrecimiento Serge Latouche (2014), que se ha referido al límite como punto de fuerza: ponerse límites como gesto que distingue la civilización de la barbarie. Por último, el filósofo Eugenio Trías ${ }^{24}$ se ha referido al límite proponiendo "pensar en términos afirmativos lo que muchas veces se piensa solamente como restricción [...]. 'Definir' tiene este mismo sentido donde la palabra límite está en juego. Y lo definido es un término" (Pérez-Borbujo, 2003, p. 37). El límite define un término y por tanto su extralimitación altera su significado y, con él, su naturaleza.

Trasladando esta reflexión al campo del urbanismo, el rebasamiento de los límites nos enfrenta al desborde entendido como exceso, la hybris a la que opone Riechmann su propuesta de autocontención. Hernández Aja ha señalado que el rebasamiento de los límites del hecho urbano conlleva "la desaparición de las ciudades en el marco de la urbanización metropolitana" (2010, p. 104). La superación de la escala urbana $^{25}$ trae la disfuncionalidad del sistema viario, la degradación de barrios centrales o la fragmentación territorial (ibíd.). Esta idea pone en primer plano el desafío civilizatorio de la sostenibilidad, que de hecho ha sido definida como una "cultura de los límites" (Gómez y Rico, 2010), una demarcación de lo ecológicamente viable y de lo socialmente aceptable.

La idea de límite en el debate urbanístico se remonta a las ideas de Howard y Geddes, pioneros del urbanismo regional, desarrolladas después por los llamados descentristas - por sus propuestas de descentralización y policentralidad urbana-, como Mumford, Stein o Bauer (Hall, 1996; Jacobs, 2013). En la actualidad, varias líneas de pensamiento reinterpretan esta tradición y convergen en la dirección de tomar el límite como recurso y oportunidad, basando sus propuestas en concebir el territorio y la metrópoli como una red de unidades interconectadas entre sí y con su entorno. Destacamos, en la escala territorial, la
22 Riechmann es uno de los autores contemporáneos que con mayor dedicación ha elaborado la idea de límite desde la ética y la ecología, desarrollada en numerosos ensayos, desde Todo tiene un limite. Ecología y transformación social (2001), Ed. Debate, hasta su conocida pentalogía de la autocontención (Ed. Catarata): 1. Un mundo vulnerable, 2. Biomímesis, 3. Gente que no quiere viajar a Marte, 4. La habitación de Pascaly 5. Todos los animales somos hermanos.

23 Auch Schönheit ist ein Lebens-Mittel. Las doce tesis de Toblach sobre desarrollo sostenible y belleza (tesis octava). Publicadas en Frankfurter Rundschau, 28 de septiembre de 1998, p. 8. Traducción de Jorge Riechmann. Disponible en versión original en: http:/ / www.apel-web.de/toblach/thes98_d.htm (abril de 2014).

24 Trías es autor de una extensa e influyente Filosofía del Límite (Cfr. Sánchez Pascual y Rodríguez Tous, 2003), desarrollada a partir de las tradiciones filosóficas que se han ocupado de la noción de límite desde Grecia hasta Hegel, Kant y Wittgenstein (Sucasas, 2003, p.339).

25 Del mismo modo lo intuyó Juan Ramón Jiménez a través de su vivencia de la ciudad de Nueva York (1982, p. 131): "Una ciudad me parece a mí que debe ser un organismo como otro cualquiera, con un límite moral y material en su desarrollo, pasado cuyo límite se convierte en vicio". 


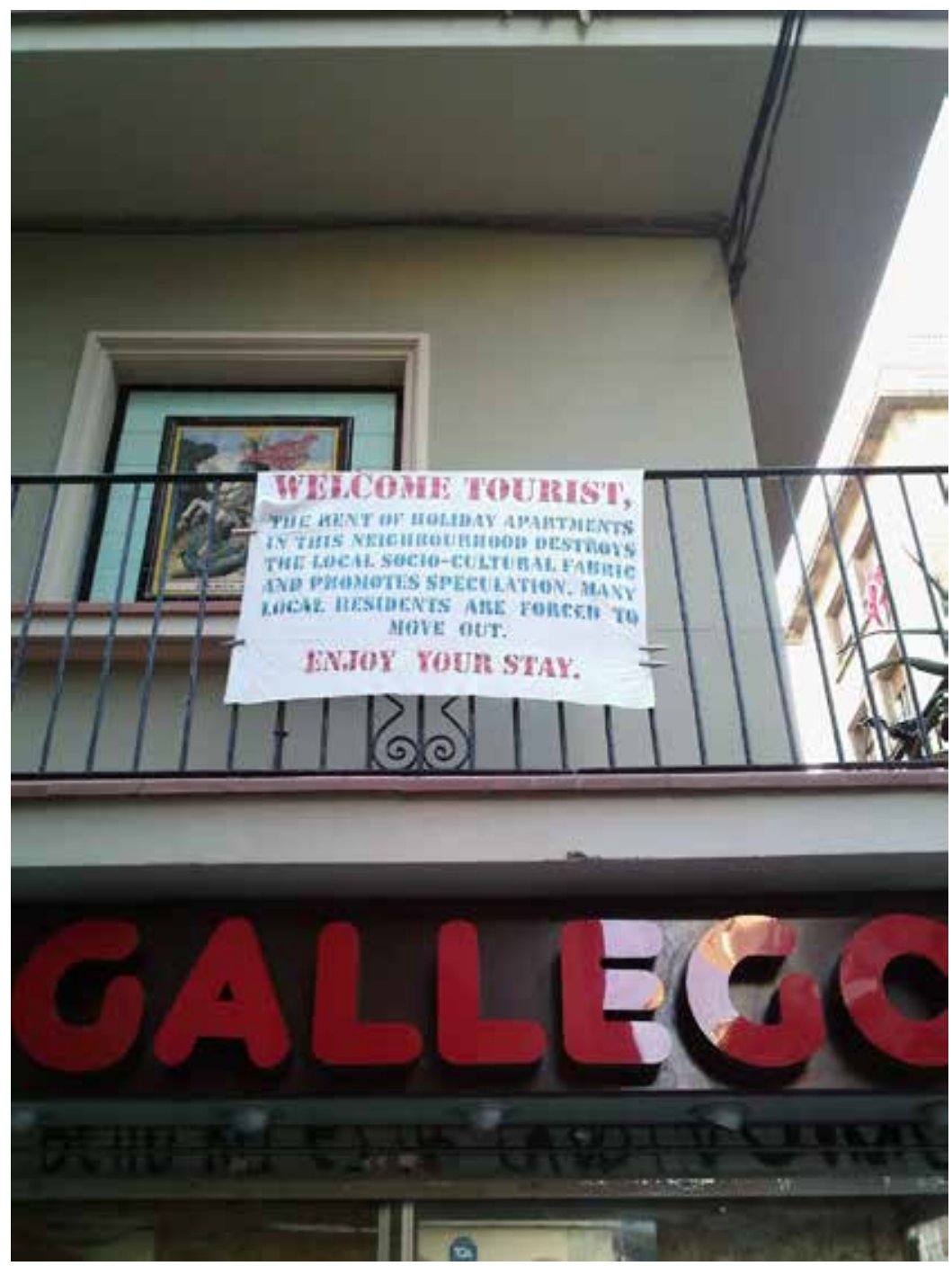

propuesta de la "bio-región" (Miller, 1999) como marco para la readaptación de la metrópolis al tamaño de su ecosistema de referencia, y más recientemente la ciudad de las aldeas (Magnaghi, 2011) o el concepto de autosuficiencia conectada (Requejo 2011a, 2011b). En la escala metropolitana cabe mencionar el constructo de Barrio-Ciudad (Hernández Aja, 1997), que nos insta a reformular la metrópoli desde un urbanismo de reforma interior y de base local. Estas posturas no implican la negación de la metrópoli sino un planteamiento transescalar e integral, dirigido a fomentar sociedades y economías de proximidad, y tendente a reubicar los sistemas urbanos en sus entornos bioregionales (Medina et al., 2014b). En ese contexto, una gestión urbana orientada a la sostenibilidad ha de reconocer igualmente la necesidad de fijar límites a otros fenómenos de desborde urbano. Uno de ellos, como se ha mencionado, es el incremento desmedido de unos usos o funciones urbanas en detrimento de otras, como el turismo en los barrios históricos (figura 7); las tipologías de gran superficie comercial frente al pequeño comercio; el empleo masivo del automóvil privado frente a otros modos de movilidad; o las grandes extensiones residenciales suburbanas.

Por su parte, en relación al concepto de frontera, resulta inspirador recordar a Mo-

Figura 7. Cartel vecinal en la Barceloneta (Barcelona), que informa a los turistas sobre los efectos negativos de su presencia masiva en el barrio. Fuente: Elaboración propia. rin, que nos explica cómo el pensamiento simplificador ha contemplado el conocimiento - y organizado la realidad - como un mosaico dividido por fronteras, mientras que según el paradigma de complejidad un dominio no se define por sus fronteras sino a partir de las relaciones que su núcleo establece con el entorno (Morin, 1990). Latouche acertó a matizar que "la frontera no aísla, sino que filtra" (2014, p. 44), y permite "encontrar la identidad necesaria para el intercambio con el otro" (ibíd.). Desde aquí se entiende la propuesta teórica del urbanismo sostenible por recuperar una ciudad compacta, mestiza y relacional, frente a la urbanización zonificada y segregada por usos homogéneos, heredada del racionalismo y exacerbada en términos de rentabilidad económica por el urbanismo global (Montaner y Muxí, 2011, pág. 124).

Hace medio siglo Jane Jacobs se refirió a los vacíos fronterizos (2013, pp. 293-305), en referencia al efecto barrera de las grandes áreas uniformes y monofuncionales, y apuntó criterios de intervención para su costura en pro de la continuidad del tejido urbano.

Quizá el más dramático ejemplo de estos vacíos fronterizos reside en el estigma social que recae sobre los barrios más degradados e ignorados de nuestras ciudades, un vacío en el imaginario de los habitantes de la ciudad que refleja la exclusión socioterritorial que padecen estos ámbitos (Torres, 2013). Afortunadamente, también a este tipo de desbordes segregadores se oponen desbordes sociopolíticos alternati- 
vos construyendo respuestas que ya están abriendo espacio a nuevas corrientes de pensamiento y acción. Hoy podemos analizar ejemplos notables de actuaciones dirigidas a la inclusión urbana de los barrios marginados, tanto en Europa como en Latinoamérica (Salas, 2005; Montaner y Muxí, 2011).

De la misma manera es preciso diseñar estrategias de intervención específicas sobre las zonas de contorno metropolitano, configuradas a base de fragmentos dispersos de urbanización monofuncional y que presentan un cuadro bien distinto de problemas de insostenibilidad. Estamos frente a otro tipo de grandes vacíos fronterizos, que contribuyen a segregar la continuidad territorial entre el medio rural y el urbano, y constituyen un modelo de hábitat deficiente y altamente dependiente de la movilidad motorizada. Pero en tanto suponen un importante reto para la sostenibilidad urbana, debemos convertirlos en áreas de oportunidad. Quizá precisamente su posición y su condición fragmentaria permita a estos ámbitos desempeñar un rol de intermediación territorial en la reconstrucción de vínculos con el espacio rural, mediante políticas de planificación que combinen la reactivación y consolidación de los usos agrarios (Magnaghi, 2011) con intervenciones estratégicas de densificación urbana que hagan viable la aparición de servicios de proximidad.

\subsubsection{Desde los actores, lógicas e intereses: poder y deseo}

Introducimos ahora una nueva pregunta acerca de los fenómenos de desborde: para qué y para quién/es supone tal desborde y qué consecuencias tiene para cada actor. En función del modelo de sociedad al que aspire quien se formule la pregunta, podremos considerarlos como situaciones deseables o no deseables, un asunto con una obvia dimensión ideológica (García, 2011). Víctor Pelli lo ilustró con lucidez tomando como ejemplo la Villa 31 de Buenos Aires, un sector urbano periférico que puede ser visto de distintas formas y, en función de lo que interprete cada observador, la acción política puede conducir "a muy diferentes caminos de acción y a muy diferentes soluciones, con diferentes consecuencias, en el hábitat general y en la sociedad" (Pelli, 2010, p. 44). Conviene por tanto centrar nuestra elaboración conceptual en marcos epistemológicos concretos y distinguir entre desbordes deseables o no deseables, según para qué y para quiénes. Un marco que, en el paradigma de sostenibilidad, concretamos en dos coordenadas interrelacionadas: viabilidad ecológica y justicia social, sobre una premisa de profundización democrática, dos ejes orientados a incrementar el buen vivir ${ }^{26}$ de las poblaciones. Una idea que cabría resumir, en el terreno del hábitat, como el derecho a la ciudad sostenible. ${ }^{27}$

Esta disquisición enlaza con una cuestión clave: el poder de unos $\mathrm{u}$ otros actores para hacer valer su visión de la realidad en los procesos de toma de decisiones, cuestión frecuentemente soslayada por los enfoques disciplinares ordinarios (Aguilera y Naredo, 2009, p. 13). Afirma Pelli: "Gestión participativa es redistribución de poder" (2007, p. 55). En este sentido, la definición de lo que resulta o no deseable, que marcará los objetivos de la acción política, debe formar parte de un proceso democrático de construcción colectiva, llevado a cabo en espacios de diálogo capaces de propiciar la participación de todos los grupos sociales cuyas vidas se ven afectadas por las decisiones en juego (Montañés, 2009). Estrategias basadas en principios de participación deberían permitir la inclusión y compatibilización de las visiones, lógicas e
$26 \mathrm{Al}$ respecto del principio del Buen Vivir se puede consultar, por ejemplo: Dávalos, P. (2008). Reflexiones sobre el sumak kawsay (el buen vivir) y las teorías del desarrollo. América Latina en movimiento. Disponible en <http:/ /alainet. org/active/25617\&lang=es $>$; Acosta, A. (2013). El Buen Vivir. Sumak Kawsay, una oportunidad para imaginar otros mundos (Ecuador). Barcelona: Icaria editorial. 27 Un Derecho a la Ciudad alejado del acusado sesgo urbanita de UN-Hábitat, cuyo discurso va demasiado "derecho a la ciudad", sino ubicado en un sentido amplio de hábitat, urbano y rural, que entiende la ciudad como un sistema complejo e inserto en la historia y en su entorno bio-regional y dependiente de sistemas más amplios (Pelli, 2010). 
intereses de todos los sectores sociales involucrados, y particularmente de los grupos más afectados y tradicionalmente alejados de la toma de decisiones: los pobladores, pero además, dentro de ellos, los colectivos que históricamente han ocupado una posición subalterna en la producción del espacio urbano: minorías étnicas, mujeres, mayores, menores y personas con movilidad reducida. Los colectivos feministas que vienen desarrollando teoría y práctica desde la perspectiva de género están generando valiosos aportes en esta dirección. ${ }^{28}$

Asumir esta perspectiva y hacerla operativa en términos de oportunidad para avanzar hacia la sostenibilidad urbana requiere concebir (y pugnar por) un marco político propicio. A este respecto resulta sugerente la idea-marco propuesta por Sousa Santos de oponer a la alianza público-privada del Estado empresario propio de las últimas décadas, una nueva articulación entre los principios de lo público y de lo comunitario, en una "reinvención solidaria y participativa del Estado" (Santos, 2009). Esto exige la democratización tanto de las orientaciones político-estratégicas como de los mecanismos de control que miden la dirección de los procesos.

Dichos mecanismos de control deberán traducirse en órganos de monitoreo y gestión participados por los actores afectados: una estructura flexible de espacios de participación que ejerza como observatorio de lógicas emergentes, actualización de objetivos y compatibilización de perspectivas entre grupos. En espacios de ese tipo se podrá generar directrices para reconducir procesos, tratar de frenar los que se consideren perjudiciales y alentar o activar desbordes creativos.

Desde el punto de vista técnico-metodológico, será oportuno incorporar actitudes y herramientas, en la línea propuesta por Villasante y otras voces expertas, para facilitar, alentar y apoyar a los movimientos de desborde sociopolítico creativo desde sus lógicas de funcionamiento y en diálogo con las lógicas de otros actores.

\subsubsection{Desde los paradigmas y los márgenes: hegemonía y alternativas}

Los márgenes para los griegos no era una línea [...]. Los márgenes era un espacio anchísimo por donde se movían los dioses más interesantes, por ahi andaba Pan, Atenea... Gente que no es del todo del centro pero que tampoco es de la selva [...]. Gente sin un lugar definido, pero gente en movimiento.

M. Ángeles Maeso. ${ }^{29}$

Nada puede reconstruirse a partir de su centro: solo sus orillas. Me tomo la libertad tal desplazamiento.

Jorge Riechmann (2001, p. 43)

los trabajos del Col·lectiu Punt6: http:// punt6.org/.

29 María Ángeles Maeso en la presentación del libro ¿Quién crees que eres yo? (2012). Editorial Huerga \& Fierro, 2012). En la Librería La Fuga, Sevilla, 2012. Archivo de audio consultado en marzo de 2014 en: https://ia800909.us.archive. org/21/items/MariaAngelesMaesoCercanias2012LaFugaLibrerias/maria\% 20angeles $\% 20$ maeso $\% 20$ cercanias $\% 202012 \% 20$ la\%20fuga \%20librer\%C3\%ADas.mp3. 
2012), y suele incluir entre estas últimas tanto a las epistemologías feministas como a las subalternas en general (Spivak, 2003). Precisamente bastardo es una de las fuentes etimológicas de la segunda acepción del DRAE para la palabra borde.$^{30}$ Cabe asignar entonces otra connotación al término des-borde: dejar de ser bastardo, salir de la situación de marginalidad en un movimiento de escape de la condición subalterna.

Por aquí nos acercamos de nuevo a la corriente poscolonial, y a la propuesta de pensamiento fronterizo crítico de Walter Mignolo. Grosfoguel lo explica como "la respuesta epistémica de lo subalterno al proyecto eurocéntrico de modernidad" no situada en un fundamentalismo antimoderno (Grosfoguel, 2006, p. 39). Y pone como ejemplo lo que aquí corresponde llamar el desborde zapatista, ya que "aceptan la noción de democracia, pero la redefinen desde la práctica y las cosmologías indígenas, definiéndola como 'el que quiera mandar debe obedecer' o 'todos somos iguales porque todos somos distintos'” (ob. cit., p. 40). También en la corriente del pensamiento poscolonial se sitúa la sociología de las ausencias y el pensamiento posabismal de Santos (2014), que remite a la propuesta de una ecología de saberes frente a la hegemonía excluyente de la epistemología occidental. En todo este vasto conjunto de iniciativas y visiones emergentes por parte de los grupos excluidos se alumbra la posibilidad de un cambio de paradigma.

Kuhn consideró los paradigmas como "realizaciones científicas universalmente reconocidas que, durante cierto tiempo, proporcionan modelos de problemas y soluciones a una comunidad científica" (2004, p. 13), y explica que la construcción de nuevos paradigmas se produce habitualmente en un contexto de conflicto y confrontación con los dominantes. Por su parte, Corvalán afirma que "El motivo de la confrontación de los paradigmas tiene que ver con la capacidad explicativa de nuevos fenómenos en la realidad" (1996, p. 13). Estas situaciones de conflicto son, por tanto, propias de los periodos históricos altamente cambiantes. Santos ha venido argumentando que "nuestro tiempo es testimonio de una crisis final de la hegemonía del paradigma sociocultural de la modernidad occidental y que, por tanto, es un tiempo de transición paradigmática" (Santos, 1995; 2000; 2010, p. 52). Y es en la periferia de los paradigmas hegemónicos donde nace el cambio y la renovación. Así lo expresa Morin, cuando explica que los cambios de un sistema solo pueden comenzar en sus márgenes (2002, p. 131): “[...] el comienzo no puede ser más que desviado y marginal... como siempre la iniciativa no puede venir más que de una minoría, al principio incomprendida, a veces perseguida".

Como sugieren las citas iniciales, es en los márgenes, como en la actitud fronteriza de Sampedro, donde se encuentra el movimiento y la potencia transformadora. Y la acción puede darse en forma de oportunidad o en forma de amenaza; las áreas de margen, en tanto ámbitos menos institucionalizados y regulados desde la ciudad central, son áreas de disputa y oportunidad (Bagnera, 2013) y registran diversos tipos de lucha por su control, como las del mercado en el suelo periurbano o las expresiones literales de violencia urbana (Carrión, 2013; Feltran, 2013). De la misma manera, es en los márgenes de los dominios establecidos de la sociedad donde tienden a aparecer las iniciativas contrahegemónicas o alternativas que con el tiempo pueden terminar abriendo paso a nuevas corrientes de pensamiento y práctica (Morin, 2002, p. 150).

Veámoslo en algunos ejemplos. El primero es la valiente iniciativa de la Corrala Utopía en Sevilla (figura 8) a cargo de un grupo de muje-
30 Del latín tardío burdus 'bastardo'; cf. burdel. Diccionario de la Real Academia Española, http://lema.rae.es/ drae/?val=borde (acceso: abril de 2014). 


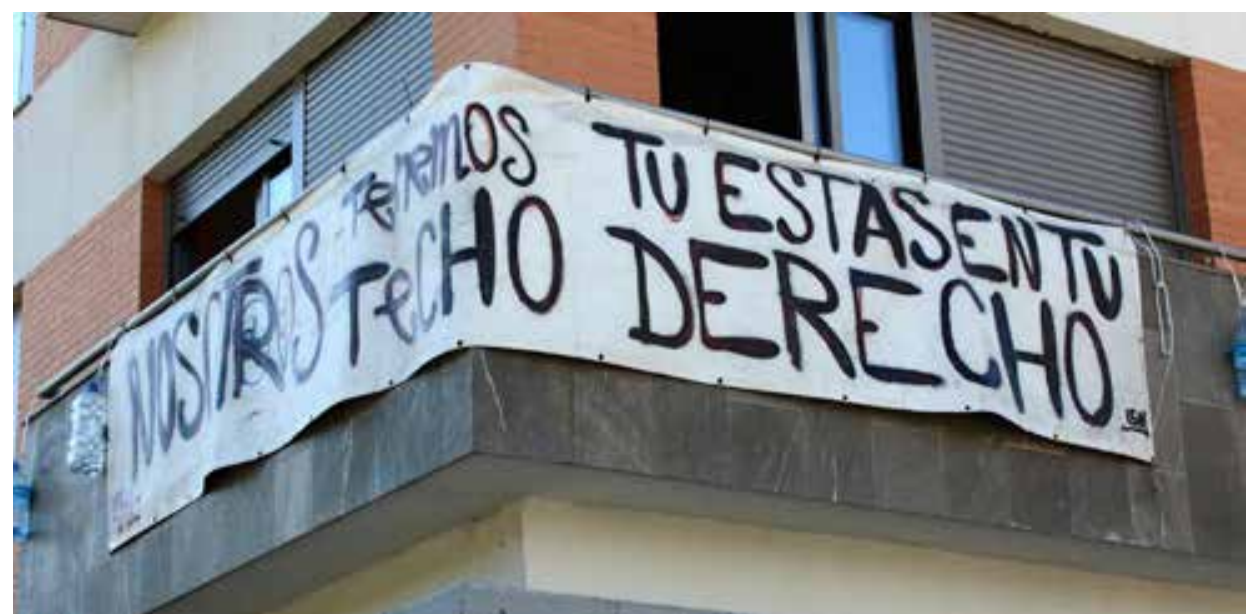

res, junto a sus redes ciudadanas de apoyo, de ocupar colectivamente un edificio vacío propiedad de una entidad bancaria. Evidenciando las limitaciones de la adjudicación individual de viviendas, este caso abrió una puerta a la innovación política en materia habitacional a través de la construcción de modelos de cogestión basados en las oportunidades de una demanda estructurada (Habitares, 2014), un campo que es preciso explorar en relación con el parque de

Figura 8. La Corrala Utopía, iniciativa pionera de ocupación en Andalucía. Fuente: Pablo Alvero Baliña.

Figura 9. Construyendo canales cortos de comercialización como factor de reconexión ciudad-campo: primer Ecomercado de Granada (mayo de 2013 ) y cartel de un encuentro de productores y consumidores. Fuente: Proyecto Planpais. viviendas desocupadas existente en nuestra región.

La actual proliferación de experiencias de agricultura ecológica urbana y periurbana a cargo de colectivos de personas desempleadas es otro buen ejemplo (Matarán, 2013; Russo et al., 2014), impulsando la construcción de sistemas locales basados en la idea de soberanía alimentaria (figura 9).

O el reciclaje de intersticios urbanos como espacios públicos, como el caso de "Esto es una plaza", un espacio olvidado de la ciudad central donde la iniciativa ciudadana convierte un solar en desuso en uno de los lugares más habitables del centro de Madrid (figura 10).

Por último, tal como han señalado los diagnósticos complejos de la marginalidad (Torres, 2013), es la ciudadanía periférica la que ha reivindicado la necesidad de renovar los enfoques institucionales en la rehabilitación de barriadas de exclusión social, facilitando la introducción en el campo del urbanismo de formas de gestión basadas en principios de integralidad y participación, o al menos suponen sus prime-

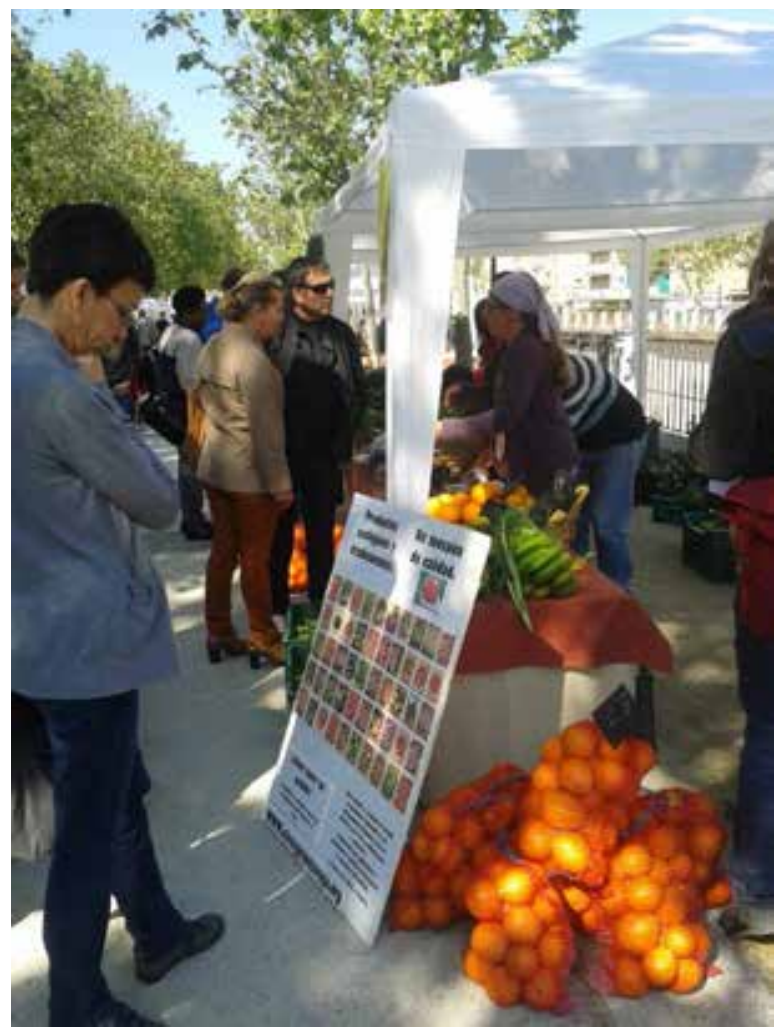

\section{EL futuro Està \\ a la huerta de la esquina}

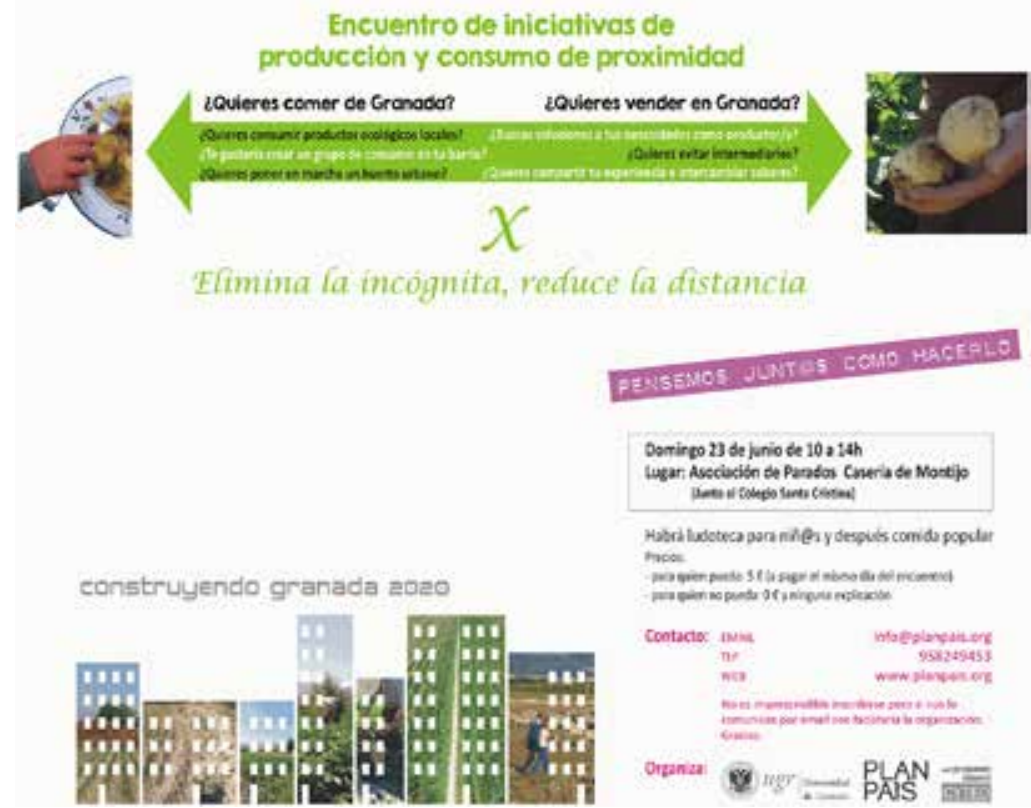


ras tentativas (figura 11) (Medina, 2012; Gallego, 2014). Valga como símbolo la iniciativa de la plataforma de entidades de Polígono Sur y su eslogan "Nosotros también somos Sevilla" como afirmación de "copresencia radical" (Santos, 2014, p. 32).

Desde esta imagen de los márgenes como ámbitos de incubación del cambio, el desborde se asocia, en términos de psicología grupal, con el concepto de emergente, como expresión colectiva de una situación latente que, en su exteriorización, tiende a modificar los esquemas de referencia anteriores (Pichon-Rivière, 1977) en un salto de lo individual a lo colectivo (Encina y Rosa, 2005), resigni-

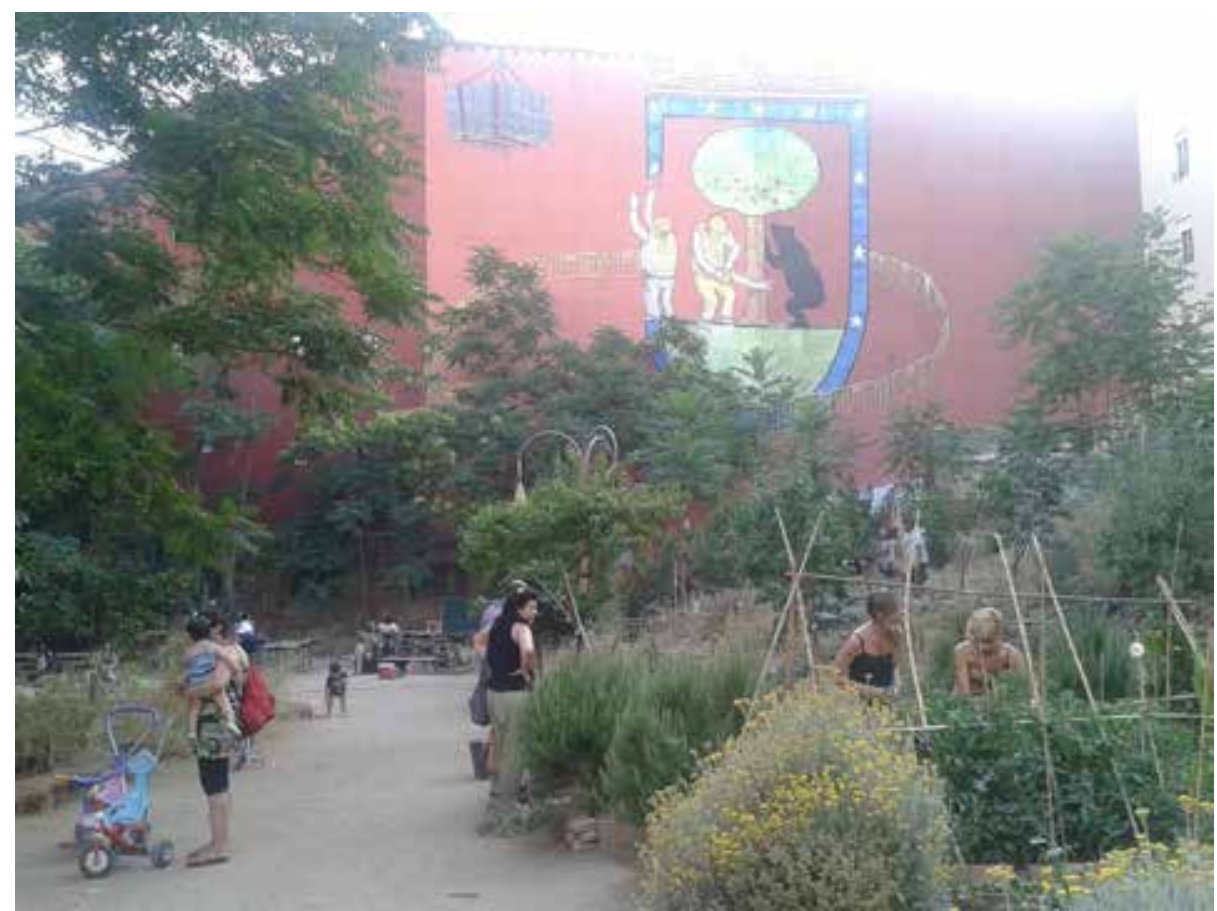
ficado desde una nueva visión que surge de los márgenes de lo consciente. De forma que lo que llamamos desbordes urbanos, situaciones que quedan fuera del control de los instrumentos existentes, puede ser un síntoma de la emergencia de nuevos fenómenos que terminen desembocando en la formulación de nuevos paradigmas que superen a los dominantes.

\section{A modo de conclusiones}

A partir de estas aproximaciones concluiremos sintetizando una serie de orientaciones, a modo de pistas conceptuales y metodológicas, que pueden resultar útiles para avanzar hacia la gestión sostenible de la ciudad y en particular para el tratamiento de las periferias urbanas:

\section{HEMEROTECA > 09/06/2002 > \\ Los vecinos del Polígono Sur urgen un Plan Integral para regenerar la zona}

\footnotetext{
- Los vecinos del Poligono Sur han reclamado a la Administración un Plan Integral para regenerar la zona que contemple al individuo dentro de la familia en su conjunto y no en programas aisladosque dificilmente atajan los problemas de raiz
}

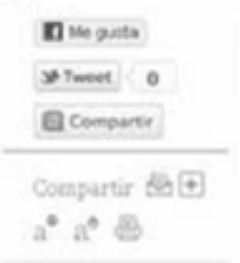

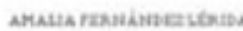

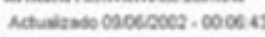

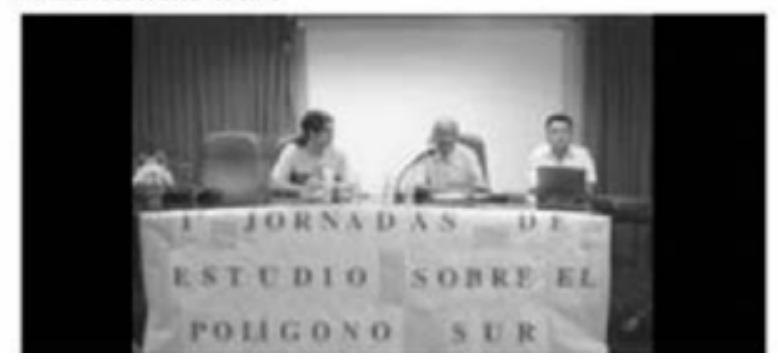

Figura 10. "Esto es una plaza", en el barrio de Lavapies. Fuente: Elaboración propia.
Figura 11. La demanda de nuevos modelos de gestión nace en la periferia social: es la iniciativa vecinal la que desencadenó el proceso que culminaría con el Plan Integral de Polígono Sur. Fuente: Hemeroteca, diario ABC (http://hemeroteca.abc.es). 
- En primer lugar, reconocer como tales los procesos urbanos que respondan a dinámicas emergentes. Ese reconocimiento será el primer paso para plantearnos cómo gestionarlas de cara a aprovechar las que supongan oportunidades o revertir las que supongan una amenaza, en función de los objetivos políticos. Cabe en este sentido plantearse la creación de mecanismos de monitoreo para la detección de fenómenos urbanos emergentes, una idea que encaja en la figura de los observatorios urbanos, sectoriales o barriales, que numerosas ciudades han puesto en marcha.

- Comprender la ciudad como el resultado de la interacción entre dos tipos de lógica: emergente y centralizada, y concebir la política, la gestión y el proyecto desde esa perspectiva. Esto implica diseñar políticas capaces de apoyar a las formas emergentes de resolución de necesidades de las poblaciones, aprendiendo de los barrios y procesos inteligentes, y poner a dialogar a ambas lógicas, innovando fórmulas de cogestión y de proyecto que aprovechen sus posibles sinergias (diseñando procesos y tipologías flexibles, por ejemplo). Si comprendemos la tensión entre desborde y control no como un enfrentamiento sino como un posible espacio de diálogo político, tendremos un soporte teórico para concebir estrategias de colaboración ${ }^{31}$ entre las lógicas autogestionarias ascendentes y las políticas institucionales de sostenibilidad que no pasen por la anulación de las primeras, ${ }^{32}$ asumiendo que será un equilibrio necesariamente conflictivo. En términos políticos esto equivale a explorar combinaciones inteligentes entre formas de democracia representativa y formas de democracia participativa.

- Asumir que el control de los procesos emergentes no puede ser sino indirecto, mediante la introducción de factores de retroalimentación, en el sentido que interese. Conviene por tanto superar la noción de control urbano entendido como un marco fijo de determinaciones y restricciones, e indagar modelos de control indirecto y sometido a marcos democráticos deliberativos: un modo de control más próximo a un espacio de gestión, donde quepan esquemas de participación y concertación entre los actores y sectores sociales involucrados. En este sentido debemos reconocer en los procesos de intervención sobre el hábitat social qué factores o criterios de gestión pueden introducir efectos de retroalimentación positiva o negativa y aprender a manejar sus combinaciones para tratar de inducir procesos inteligentes. Por ejemplo, la introducción de un conjunto sinérgico de estímulos fiscales, económicos y pedagógicos ha ayudado al Ayuntamiento de Rubí a desplegar una exitosa política energética local..$^{33}$

31 Sobre esta premisa se apoya el proyecto andaluz de $\mathrm{I}+\mathrm{D}+\mathrm{i}$ Barrios en transición, ligado a la trayectoria de la red dBU (De Manuel et al., 2013; Medina et al., 2014a y 2014b).

32 Recordemos la advertencia de Zibecchi (2010) acerca de los desbordes de los sectores subalternos frente a las estrategias del Estado para abducirlos bajo formas de relación no conflictiva, convirtiendo los movimientos populares en organizaciones sociales.

33 Programa Rubí Brilla: http://www. rubi.cat/es/ayuntamiento/proyectos-estrategicos/rubibrilla?set_language $=\mathrm{es}$. 
- Desde una comprensión compleja de lo urbano, la idea de frontera entendida no como separación sino como ámbito de relación nos lleva a situar las intervenciones sobre las periferias urbanas en planteamientos integrales de ciudad, que contemplen su funcionamiento sistémico, multidimensional y multiescalar (Gallego, 2014). En ese contexto, podemos plantearnos cómo responder a los atributos de periferia que suponen debilidades o amenazas mediante la introducción de atributos de centralidad (barrial, urbana y/o metropolitana) con criterios de integralidad, participación y control de la gentrificación. Esto nos lleva a pensar en la posibilidad de planificar y gestionar la ciudad procurando distintos nodos y escalas de centralidad, mediante una red de entornos urbanos basados en la proximidad y la calidad urbana para la vida cotidiana (Ciocoletto et al., 2014). Frente a las grandes operaciones del urbanismo global, esta perspectiva nos trae la imagen de un urbanismo distribuido, a base de múltiples intervenciones de mejora urbana de pequeña y mediana escala, incidiendo desde lo físico, lo político y lo sociocultural (Capel, 2003; De Manuel, 2010; Medina, 2012).

- La proximidad requiere un umbral mínimo de densidad urbana, de otro modo no es viable un sistema dotacional, comercial o de movilidad. En este sentido el límite a la expansión territorial también nos sugiere la oportunidad de planificar el territorio metropolitano con el criterio de estructurar los fragmentos de periferia dispersa, mediante operaciones de densificación y mezcla de usos y perfiles poblacionales, conectándolos al resto de la ciudad a través de sistemas estructurantes de espacios libres, transporte público y dotaciones.

Cabría agregar otras orientaciones y matices a esta reflexión, que por otro lado no viene tanto a innovar como a reforzar criterios propugnados desde otras corrientes de pensamiento y acción, algunas de ellas desde hace varias décadas, pero aún con una presencia insuficiente en el imaginario profesional y político.

En un incierto periodo de crisis múltiples como el que afrontamos, Santos (2009) aboga por un Estado convertido en un terreno de experimentación institucional en el que convivan por un tiempo distintas soluciones que, a modo de experiencias piloto, puedan ser sometidas al control y la evaluación ciudadana democrática. Es preciso acentuar la interacción y la convergencia entre todas esas elaboraciones y prácticas alternativas, apuntando hacia una transición de fase que las haga emerger de su condición todavía periférica y las articule como un paradigma central de la cultura política y profesional. Para expresarlo en los términos empleados por Riechmann o Sampedro, concluiremos afirmando la necesidad de construir colectivamente un urbanismo fronterizo basado en epistemologías alternativas a las dominantes, llamado a integrar y superar - a desbordar - la teoría y praxis del urbanismo instituido para refundarlo en claves de transición socioecológica, tal como demandan los retos urbanos y civilizatorios que nos plantea el siglo XXI. 


\section{Referencias bibliográficas}

Aguilera, F. y Naredo, J. M.(2009). Introducción. En aguilera y Naredo (eds.), Economía, poder y megaproyectos. Lanzarote: Fundación César Manrique, pp. 13-18.

Alba Rico, S. (2014). La izquierda, los inmigrantes y los derechos de los españoles. Cuarto poder, 24 de marzo de 2014. Recuperado el 20 de abril de 2014, de: http:/ / www.cuartopoder.es/tribuna/la-izquierda-los-inmigrantes-y-los-derechos-de-los-espanoles $/ 5624$.

Arias, D. (2013). Crónicas del Desborde. En VV.AA., [Des]Bordes Urbanos (VP Monografías, n. ${ }^{\circ}$ 01). Montevideo: Unidad Permanente de Vivienda, Facultad de Arquitectura, UdelaR, pp. 15-26.

Arias, F. La "permanencia" histórica de los barrios desfavorecidos. Biblioteca $\mathrm{CF}+\mathrm{S}$ Ciudades para un futuro más sostenible. Recuperado el 20 de diciembre, de 2014, de: http:/ / habitat.aq.upm.es/bv/gbd15. html.

Arteaga, I. (2005). De periferia a ciudad consolidada. Estrategias para la transformación de zonas urbanas marginales. Bitácora urbano\territorial, 9 (1), pp. 98-111.

Bagnera, P. (2013). Los Bordes: espacios de indagación, gestión e intervención urbana. En VV.AA., [Des]Bordes Urbanos (VP Monografías, nº 01). Montevideo: Unidad Permanente de Vivienda, Facultad de Arquitectura, UdelaR, pp. 27-36.

Bauman, Z. (1999). Modernidad líquida. Buenos Aires: Fondo de Cultura Económica.

Benítez, J. (2010). Obsolescencias en barrios andaluces. El caso del barrio de San Martín de Porres. En VVAA, Revista Ciudad Viva: Obsolescencias urbanas (n. ${ }^{\circ}$ 3). Sevilla: CVOT- EPSA, pp. 6-10

Boff, L. (2010). La dignidad de la tierra. Ecología, mundialización, espiritualidad. La emergencia de un nuevo paradigma. Madrid: Trotta.

Braidotti, R. (2011). Nomadic Theory. The portable Rosi Braidotti. Columbia University Press.

Capel, H. (2003). Los problemas de las ciudades. Urbs, Civitas y Polis. En VVAA., Ciudades, arquitectura y espacio urbano (Colección Mediterráneo Económico, no3 ). Almería: I.E.S. Cajamar.

Carrión, F. (2013). En el límite de la vida: la violencia fronteriza. En Carrión, F., Mejía, D., Espín, J. (comp.), Aproximaciones a la frontera. Quito: FLACSO, pp. 95-105.

Castrillo, M. (2010). Hacia un urbanismo más justo: reflexiones sobre la rehabilitación de los barrios periféricos en España. En MUSSET, A., Ciudad, sociedad, justicia: un enfoque espacial y cultural. Mar del Plata: EUDEM, pp. 237-274.

Cavalcanti, C. (2005). Celso Furtado y el subdesarro- llo. Revista Venezolana de Economía y Ciencias Sociales, 11. Recuperado el 10 de mayo de 2014, de: http:/ / www.redalyc.org/articulo.oa?id=17711102.

Caveri, C. (2002). Una frontera caliente. La arquitectura americana entre el sistema y el entorno. Buenos Aires: Sintaxis.

Ciocoletto, A. y Col-Lectiu Punt6 (2014). Espacios para la vida cotidiana. Auditoría de Calidad Urbana con perspectiva de Género. Barcelona: Comanegra.

Corvalán, J. (1996). Los paradigmas de lo social y las concepciones de intervención en la sociedad. (Extracto de tesis doctoral). Bélgica: Universidad Católica de Lovaina. Recuperado el 15 de abril de 2014, de: http:/ / es.scribd.com/doc/108786970/Los-paradigmas-de-lo-Social-y-las-concepciones-de-intervencionen-la-Sociedad-Javier-Corvalan.

Cyted (2011). Anexo I a la Convocatoria 2010. Lineas de Investigación Abiertas para la Convocatoria 2011 de Acciones Cientifico-Tecnológicas del Programa CYTED. Madrid: CYTED.

De Manuel Jerez, E. (2010). Construyendo triángulos para la gestión social del hábitat. Hábitat y Sociedad, 1, pp. 13-37. Recuperado el 15 de septiembre de 2015, de: http://acdc.sav.us.es/habitatysociedad/ images/stories/N01/N01_completo1.pdf.

De Manuel Jerez, E. et al. (2013). Barrios en transición. Hábitat y sociedad, 5, pp. 35-55. Recuperado el 15 de septiembre de 2015, de: http://acdc. sav.us.es/habitatysociedad/images/stories/N05/ N05A03\% 20Barrios\%20en\% 20transicion.pdf.

Fariña, J. Estas ciudades son una ruina. El blog de José Fariña, 12 de enero de 2014. Recuperado el 15 de marzo de 2014, de: http:/ / elblogdefarina.blogspot.com.es/2014/01/estas-ciudades-son-una-ruina. html.

Feltran, G.(2013). Violencia urbana, ciudad democrática y derecho a la ciudad. Debate con Erminia Maricato en el Seminário Internacional (Des)Bordes Urbanos e Assembléia Anual da Rede Cyted, 26 e 27 de julio 2013. LABHAB, FAUUSP: São Paulo.

Fernández, R. (2006). El Tsunami urbanizador español y mundial. Barcelona: Virus.

(2010). Un planeta de metrópolis (en crisis). Zambra, Baladre, CGT y Ecologistas en Acción.

García, J. (2007). Coranomía. Los universales de la urbanística: estudios sobre las estructuras generativas de las ciencias del territorio. Síntesis selectiva de la Tesis doctoral. ACE: Arquitectura, Ciudad y Entorno, 3 (II), pp. 210-278.

García, A. (2011). La calle a escena. El sistema de espacio público de Sevilla y su entorno metropolitano, retos y posibilidades. Sevilla: Ayuntamiento de Sevilla.

García, A., Ojeda, J. F. y Torres, F.J. (2008). Hacia una 
nueva lectura de las ciudades y sus espacios: Ausencias y emergencias en la ciudad inteligente. En García, A. (coord.), Espacios públicos, ciudades y conjuntos históricos. Sevilla: Instituto Andaluz de Patrimonio Histórico, pp. 145-161.

Gesto, B. y Perea, L. (coord.) (2012). Evaluando la Habitabilidad Básica: Una propuesta para proyecto de cooperación (Colección: Red Universitaria de Investigación para Cooperación para el Desarrollo). Madrid: Catarata.

Gómez-Baggethun, E. y Rico García-Amado, L. (2010). Sostenibilidad: Cultura de los límites. En VV.AA., Claves del ecologismo social. Madrid: Libros en Acción, EeA.

Grosfoguel, R. (2006). La descolonización de la economía política y los estudios postcoloniales: transmodernidad, pensamiento fronterizo y colonialidad global. Tabula Rasa. Recuperado el 18 de mayo de 2014, de: http://www.redalyc.org/articulo. oa?id=39600402.

Encina, J. y Rosa, M. (2005). Haciendo metodología al andar. En ENCINA, J. et al. (coords.), Cuando nos parece que la gente no participa. Sevilla: Atrapasueños, Unilco, Ayto. Palomares del Río, pp. 44-63.

Encina, J. y Ávila, M.A. (2014). El desempoderamiento. Viviendo la construcción de un nuevo mundo sin poder. Autonomía E Autogestión, pp. 175-246. Recuperado el 19 de abril de 2015, de: http:/ /ilusionismosocial.org $/ \mathrm{mod} / \mathrm{resource} /$ view.php?id=619.

Gallego, C. (2014). Herramienta para el análisis de estrategias de intervención urbana inclusivas e integradas. III Jornadas de Arquitectura y Cooperación, ArCaDia III. UPM, Madrid.

Giménez, E. (2014). Entrevista a Sandra Aída Visokolskis. El Litoral. Ocio trabajado, 20 de junio de 2008. Recuperado el 12 de febrero de 2014, de: http:// blogs.ellitoral.com/ocio_trabajado/2008/06/20/ las-metaforas-se-infiltran-ubicuamente-en-todo-terreno/.

Habitares. Adjudicación de viviendas públicas en alquiler: responder a la demanda estructurada no es una utopía. La Ciudad Viva, 14 de abril de 2014. Recuperado el 14 de abril de 2014, de: http://www.laciudadviva.org/blogs $/$ ?p=22709.

Hall, P. (1996). Ciudades del mañana. Historia del urbanismo en el siglo XX. Barcelona: Serbal.

Hernández, A. (dir.) (1997). La ciudad de los ciudadanos. Madrid: Ministerio de Fomento.

. (2010). Urbanización contra sostenibilidad. En VV.AA., Claves del ecologismo social. Madrid: Libros en Acción, EeA.

Holland, M.M. et al. (eds.) (1991). Ecotones. Chapman and Hall, New York, London.

Holloway, J. (2005). Cambiar el mundo sin tomar el poder. Caracas: Vadell.

Jacobs, J. (2012). Muerte y vida de las grandes ciudades. Madrid: Capitán Swing.
Jiménez, J.R. (1982). Límite del progreso o la debida proporción. Política poética, Alianza, Madrid.

Johnson, S. (2008). Sistemas emergentes. O qué tienen en común hormigas, neuronas, ciudades y software. Madrid: Turner/Fondo de Cultura Económica.

Kuhn, T.S. (2004). La estructura de las revoluciones científicas. México: Fondo de Cultura Económica. Primera edición en inglés, 1962. Primera edición en español (FCE, México), 1971. Octava reimpresión (FCE, Argentina), 2004. Título original: The structure of scientific revolutions, 1962, University of Chicago Press.

Latouche, S. (2014). Limite. Buenos Aires: Adriana Hidalgo.

López Medina, J. M. (2012). El diseño participativo en programas de rehabilitación de viviendas. Universidad de Sevilla. Tesis doctoral (inédita).

López Medina, J. M. et al. (2014a). La Vivienda Colectiva en el "Siglo de la Gran Prueba". Diseño y gestión social de la vivienda colectiva en procesos de transición hacia la sostenibilidad. Actas del I Congreso Internacional de Vivienda Colectiva Sostenible. Barcelona: UPC, pp. 424-429.

López Medina, J. M. et al. (2014b). Transición socioecológica en ámbitos urbanos metropolitanos: (re) construyendo barrios a escala humana. Revista de Economía Crítica, 17, pp. 136-154.

Lorenzo, P. (2013). El hábitat y los desbordes urbanos. Criterios para el análisis y la mejora. En VV.AA., [Des]Bordes Urbanos (VP Monografías, n. ${ }^{\circ} 01$ ). Montevideo: Unidad Permanente de Vivienda, Facultad de Arquitectura, UdelaR, pp. 37-50.

Magnaghi, A. (2011). El proyecto local. Revista Arquitectonics. Barcelona: Universidad Politécnica de Cataluña.

Matarán, A. (2013). Participación social en la protección activa de los espacios agrarios periurbanos: un estado de la cuestión. Boletín de la Asociación de Geógrafos Españoles, 63, pp. 57-79.

Matarán, A., Dimuro, G. y De Manuel, E. (2013). Reflexiones sobre el concepto de desbordes. En VV.AA., [Des]Bordes Urbanos. (VP Monografías, n. ${ }^{\circ}$ 01). Montevideo: Unidad Permanente de Vivienda, Facultad de Arquitectura, UdelaR, pp. 51-56.

Mato, J. (1984). Desborde popular y crisis del Estado. Lima: Instituto de Estudios Peruanos.

Max-Neef, M., Elizalde, A. y Hopenhayn, M. (1994). Desarrollo a Escala Humana. Barcelona: Nordan-Comunidad e Icaria Editorial (Segunda Edición de 1998).

MED European Program (2013). LIMIT4WeDA: Light Mobility and Information Technologies for Weak Demand Areas. Programa MED: http://www.limit4weda.eu/.

Miller, K. What is bioregional planning? (1999). En Crofts, R., Maltby, E., Smith, R. y Maclean, L. (eds.). Integrated Planning: International Perspectives, Battleby, Scotland 7-9 April 1999: IUCN \& Scottish Natural Heritage. 
Monedero, J. C. (2013). Curso urgente de política para gente decente. Barcelona: Seix Barral.

Montaner, J. M. (1999). Arquitectura y crítica. Barcelona: GG Básicos (2007 segunda edición).

Montaner, J. M. y Muxí, Z. (2011). Arquitectura y política. Ensayos para mundos alternativos. Barcelona: Gustavo Gili.

Montañés, M.(2009). Metodología y técnica participativa. Teoría y práctica de una estrategia de investigación participativa. Barcelona: UOC.

Morin, E. (1990). Introducción al pensamiento complejo. Barcelona: Gedisa.

- (2000). La mente bien ordenada. Barcelona: Seix Barral (2002, cuarta edición).

Muxí, Z. (coord.) (2003). Postsuburbia. Rehabilitación de urbanizaciones residenciales monofuncionales de baja densidad. Barcelona: Comanegra.

Naredo, J. M. (2003). Instrumentos para paliar la insostenibilidad de los sistemas urbanos. En Arenillas, T., Ecología y Ciudad. Raíces de nuestros males y modos de tratarlos. Madrid: El Viejo Topo.

Odum, E. P. (1971). Fundamentals of Ecology. W.B. Saunders Company, Philadelphia, Pennsylvania. U.S.A.

Ojeda, J. F. (1999). Naturaleza y desarrollo. Cambios en la consideración política de lo ambiental durante la segunda mitad del siglo XX. Papeles de Geografia, 30, pp. 103-117.

- (2009). Ciudad, metrópolis, postmetrópolis y el uso de la inteligencia compartida. En VV.AA., $R e^{-}$ vista Ciudad Viva (Congreso Internacional La ciudad viva como urbs, Quito, julio de 2009). Sevilla: COPT.

Pérez-Borbujo, F. (2003). Ensayo y sistema. Entrevista a Eugenio Trías. En Sánchez, A. y Rodríguez, J.A. (eds.), Eugenio Trías: El limite, el símbolo y las sombras. Barcelona: Destino, pp. 13-58.

Pelli, V.S. (2007). Habitar, participar, pertenecer: acceder a la vivienda, incluirse en la sociedad. Buenos Aires: Nobuko.

— (2010). La gestión de la producción social del hábitat. Hábitat y Sociedad, 1, pp. 39-54. Recuperado el 15 de septiembre de 2015, de: http:/ /acdc. sav.us.es/habitatysociedad/images/stories/N01/ n01a02_la_gestion_del_la_produccion_social_del_ habitat.pdf.

Pichon-Rivière, E. (1977). Concepto de ECRO. Temas de Psicología Social, 1, (1).

Requejo, J. (2011a). Territorio y energía: la autosuficiencia conectada. A.T.Clave, SL. Recuperado el 6 de abril de 2014, de: http:/ /www.atclave.es/publicaciones/descargas/pub_desarrollo/27_territorio_ energial.html.

- (2011b). Territorio y energía. Orden mecánico versus orden orgánico. Hábitat y Sociedad, 2, pp. 33-47. Recuperado el 15 de septiembre de 2015, de: http://acdc.sav.us.es/habitatysociedad/images/stories/N02/n02a02_territorio_y_energa.pdf.
Riechmann, J. (2001). Desandar lo andado. Madrid: Hiperión.

_. (2001). Crear ciudades y pueblos sostenibles. Tratar de comprender, tratar de ayudar. Blog de Jorge Riechmann, 2011. Recuperado el 22 de abril de 2012, de: http:/ / tratarde.org/docencia-en-la-uam.

- 2004). Gente que no quiere viajar a Marte. Ensayos sobre ecología, ética y autolimitación. Madrid: Los libros de la catarata.

—_ (2006). Biomímesis. Ensayos sobre imitación de la naturaleza, ecosocialismo y autocontención. Madrid: Los libros de la catarata.

Rist, G. (2002). El desarrollo: historia de una creencia occidental. Madrid: Los libros de la Catarata.

Russo, F. (2014a). (des)Bordes Urbanos \#1: "Políticas, proyecto y gestión sostenible en la ciudad de la periferia”. Entrevista a Salvador Schelotto. La Ciudad Viva, 7 de enero de 2014. Recuperado el 17 de marzo de 2014, de: http:/ /www.laciudadviva.org/ blogs $/$ ?p=20578.

Russo, F. et al. (2014b). La agricultura de proximidad como recurso para la restauración ecológica y la diversificación económica local. La experiencia participativa de las Asociaciones de Parados en el sector norte de Granada. II Congreso de agricultura ecológica urbana y periurbana. Huertos urbanos, autoconsumo y participación social. Utrera (Sevilla), 13, 14 y 15 de marzo de 2014. Sociedad Española de Agricultura Ecológica (SEAE).

Salas, J. (2005). Mejora de barrios precarios en Latinoamérica. Bogotá: Escala.

Sampedro, J. L. (1991). Desde la frontera. Discurso de ingreso en la Real Academia Española. Madrid.

Schelotto, S. (2013). Introducción. En VV.AA., [Des] Bordes Urbanos (VP Monografías, n. ${ }^{\circ}$ 01). Montevideo: Unidad Permanente de Vivienda, Facultad de Arquitectura, UdelaR, pp. 7-14.

Schelotto, S. et al. (2011). (Des)Bordes Urbanos. Politica, proyecto y gestión sostenible en la ciudad de la periferia. Formulario de solicitud de la propuesta. Montevideo: Programa CYTED.

Schelotto, S. (comp.) (2013). [Des]Bordes Urbanos. Política, proyecto y gestión sostenible en la ciudad de la periferia. En VV.AA., [Des]Bordes Urbanos (VP Monografías, n. ${ }^{\circ}$ 01). Montevideo: Unidad Permanente de Vivienda, Facultad de Arquitectura, UdelaR.

Sloterdijk, P. (2003). Esferas I. Burbujas. Madrid: Siruela.

- (2005). Esferas III, Espumas. Barcelona: Siruela.

Solá-Morales, M. (dir.) (1992). Projectar la perifèria. Urbanisme Revista (UR), pp. 9-10 (Laboratori d'Urbanisme de Barcelona, ETSA UPG).

Sousa Santos, DE, B. (1999). Reinventar la democracia, reinventar el Estado. Madrid: Ediciones Sequitur (2009, segunda edición).

— (2010). Para descolonizar Occidente. Más allá del pensamiento abismal. Buenos Aires: CLACSO. 
Spivak, G. (2003). ¿Puede hablar el subalterno? Revista Colombiana de Antropología, 39, pp. 297-364.

Sucasas, A. (2003). Pensar la frontera. La filosofía del límite de Eugenio Trías. Sánchez, A. y Rodríguez, J.A. (eds.), Eugenio Trías: El límite, el símbolo y las sombras. Barcelona: Destino.

Sugranyes, A. (2013). Desbordes a la chilena. En VV.AA., [Des]Bordes Urbanos (VP Monografías, n. ${ }^{\circ}$ 01). Montevideo: Unidad Permanente de Vivienda, Facultad de Arquitectura, UdelaR, pp. 57-66.

Till, J. (2014). Soft Housing. Actas del I Congreso Internacional de Vivienda Colectiva Sostenible. Máster Laboratorio de la Vivienda Sostenible del siglo XXI. Barcelona: Fundació UPC, pp. 50-53.

Torres, F.J. (2013). Segregación urbana y exclusión social en Sevilla. El paradigma Polígono Sur. Sevilla: Universidad de Sevilla.

Villasante, T.R. (2006a). Desbordes Creativos. Estilos y estrategias para la transformación social. Madrid: Los libros de la catarata.

. (2006b). Reversión y desborde popular. $R E$ -

DES-Revista hispana para el análisis de redes sociales, 2, p. 11.

. (2014). Redes de vida desbordantes. Fundamentos para el cambio desde la vida cotidiana. Madrid: Los libros de la catarata.
Wallerstein, I. (1996). Después del liberalismo. México: Siglo XXI.

Zalaquett, C. (2012). Ciencia y género: lo legítimo y lo bastardo en epistemología científico-social. Izquierdas. Una mirada histórica desde América Latina,12 de abril de 2012, pp. 26-51. Recuperado el 10 de julio de 2013, de: http://www.izquierdas.cl/revista/wp-content/uploads/2012/04/ Epistemolog\%C3\%ADas-feministas.pdf.

Zarza, D. (2001). DEsBORDES URBANOS. CIRCO, Serie 4. : El corazón del tiempo, 83. Madrid: Mansilla, Rojo y Tuñón. Recuperado el 17 de marzo de 2014, de: http://www.mansilla-tunon.com/circo/epoca4/pdf/2001_083.pdf.

Zibechi, R. (2006). Dispersar el poder. Buenos Aires: Tinta Limón.

- (2007). Autonomías y emancipaciones. América Latina en movimiento. Lima: Programa Democracia y Transformación Global, Fondo Editorial de la Facultad de Ciencias Sociales (Universidad Nacional Mayor de San Marcos).

- (2010). Movimientos y emancipaciones. Del desborde obrero de los "60 al "combate a la pobreza". Montevideo: Alter.

LÓPEZ MEDINA, José María. Des-Bordes urbanos: un concepto en construcción. Hábitat y Sociedad, 2014, n. ${ }^{\circ}$ 7, pp. 15-41.

$<$ www.habitatysociedad.us.es $>$ http://dx.doi.org/10.12795/HabitatySociedad.2015.i8.02

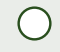

